\title{
doi:10.1016/S0016-7037(03)00454-X
}

\section{Glasses in the D'Orbigny angrite}

\author{
Maria Eugenia Varela, ${ }^{1, *}$ Gero Kurat, ${ }^{2}$ Ernst Zinner, ${ }^{3}$ Nicole Métrich, ${ }^{4}$ Franz Brandstätter, ${ }^{2}$ \\ Theodoros NTAflos, ${ }^{5}$ and Paul Sylvester ${ }^{6}$ \\ ${ }^{1}$ CONICET-UNS, Dpto de Geologia, San Juan 670, 8000, B. Blanca, Argentina \\ ${ }^{2}$ Naturhistorisches Museum, Postfach 417, A-1014, Vienna, Austria \\ ${ }^{3}$ Laboratory for Space Sciences and Physics Department, Washington University, St. Louis, MO 63130, USA \\ ${ }^{4}$ Laboratory Pierre Süe, CEA-CNRS, Saclay, F-91191, Gif sur Yvette, France \\ ${ }^{5}$ Institut für Geologische Wissenschaften, Universität Wien, Althanstrasse 14, A-1090 Vienna, Austria \\ ${ }^{6}$ Department of Earth Sciences, Memorial University of Newfoundland, St. John's, NF A1B 3X5, Canada
}

(Received January 2, 2003; accepted in revised form May 28, 2003)

\begin{abstract}
The angrites are a small and heterogeneous group of achondritic meteorites with highly unusual chemical and mineralogical features. The abundant presence of glasses in D'Orbigny makes this rock a unique member of the angrite group. Glasses fill open spaces, form pockets, and occur as inclusions in olivines. Their physical settings exclude an incorporation from an external source. Major and trace element (rare earth elements [REE], Li, B, Be, transition elements, $\mathrm{N}$ and $\mathrm{C}$ ) contents of these glasses and host olivines were measured combining laser ablation inductively coupled plasma mass spectrometry (LA-ICP-MS), secondaryion mass spectrometry (SIMS), Nuclear Reaction Analysis (NRA), and EMP techniques. Based on the major element composition, glasses filling voids could represent either a melt formed by melting an angritic rock or a melt from which angrites could have crystallized. Trace element contents of these glasses strongly indicate a direct link to the D'Orbigny bulk meteorite. They are incompatible with the formation of the glasses by partial melting of a chondritic source rock or by shock melting. The refractory elements (e.g., $\mathrm{Al}, \mathrm{Ti}, \mathrm{Ca}) \mathrm{have}$ about $10 \times \mathrm{CI}$ abundances with $\mathrm{CaO} / \mathrm{TiO}_{2}$ and $\mathrm{FeO} / \mathrm{MnO}$ ratios being approximately chondritic. Trace element abundances in the glasses appear to be governed by volatility and suggest that the refractory elements in the source had chondritic relative abundances. Although the glasses (and the whole rock) lack volatile elements such as $\mathrm{Na}$ and $\mathrm{K}$, they are rich in some moderately volatile elements such as $\mathrm{B}, \mathrm{V}, \mathrm{Mn}, \mathrm{Fe}$ (all with close to $\mathrm{CI}$ abundances), and $\mathrm{Li}$ (about 3-5 $\times \mathrm{CI}$ ). These elements likely were added to the glass in a sub-solidus metasomatic elemental exchange event. We have identified a novel mechanism for alteration of glass and rock compositions based on an exchange of $\mathrm{Al}$ and $\mathrm{Sc}$ for Fe and other moderately volatile elements in addition to the well-known metasomatic exchange reactions (e.g., $\mathrm{Ca}-\mathrm{Na}$ and $\mathrm{Mg}-\mathrm{Fe}$ ).

Because glass inclusions in olivine were partly shielded from the metasomatic events by the host crystal, their chemical composition is believed to be closer to the original composition than that of any other glasses. The relative trace element abundances in glasses of glass inclusions in olivine and glass pockets are also unfractionated and at the 10 to $20 \times \mathrm{CI}$ level. These glasses are chemically similar to the common void-filling glasses but show a much wider compositional variation. Inclusion glasses demonstrate that at least olivine grew with the help of a liquid. In analogy to olivines in carbonaceous chondrites, initial formation could also have been a vapor-liquid-solid condensation process. At that time, the glass had a purely refractory composition. This composition, however, was severely altered by the metasomatic addition of large amounts of $\mathrm{FeO}$ and other moderately volatile elements. The presence of volatile elements such as carbon and nitrogen in glasses of glass inclusions is another feature that appears to give these glasses a link with those hosted by olivines of carbonaceous chondrites. All these features point to an origin from a vapor with relative abundances of condensable elements similar to those in the solar nebula. Copyright (C) 2003 Elsevier Ltd
\end{abstract}

\section{INTRODUCTION}

Angrites are a small group of rocks as old as the solar system: the $\mathrm{U}-\mathrm{Pb}$, Th- $\mathrm{Pb}$, and $\mathrm{Pb}-\mathrm{Pb}$ ages for Angra dos Reis, LEW 86010 and D'Orbigny are between 4.54 and $4.5578 \mathrm{Ga}$ (Wasserburg et al., 1977; Lugmair and Galer, 1992; Jagoutz et al., 2002). The genesis of these rocks is highly controversial: "There is uncertainty as to whether they are direct melts of fractionated, or unfractionated, nebular components, or are fractionated planetary melts or both" (Prinz and Weisberg, 1995). The controversy is due to the unusual mineralogy, petrology, geochemistry, and isotopic features of angrites. An-

\footnotetext{
* Author to whom correspondence should be addressed (evarela@criba.edu.ar).
}

grites show a particular mineralogy, consisting of aluminumtitanium augite, anorthite, and olivine, with kirschsteinite, phosphates, Fe-Ni metal, and sulfides (Prinz et al., 1977, 1988; Goodrich, 1988; McKay et al., 1988, 1990; Prinz and Weisberg, 1995; Mikouchi et al., 1996; Mikouchi and McKay, 2001). All phases are usually out of equilibrium with one another (Kurat et al., 2002). In addition, the refractory elements have abundances at $10-15 \times \mathrm{CI}$ abundances similar to those in $\mathrm{Ca}, \mathrm{Al}$-rich inclusions in carbonaceous chondrites and to those in eucrites. The deficit in siderophile elements as compared to refractory lithophile elements clearly mimics that of eucrites (Prinz et al., 1988, 1990; Prinz and Weisberg, 1995; Jones et al., 1988). Notwithstanding their peculiar properties, angrites are widely believed to be igneous rocks of basaltic composition. 
The new angrite D'Orbigny, found in the Buenos Aires province of Argentina, is the largest member of the six angrites known up to date $(16.55 \mathrm{~kg})$. The front and backsides of this meteorite consist of a medium to coarse-grained subophitic textured rock, with a porous, coarse-grained rock in between them (Kurat et al., 2001a,b). Recent petrographic and geochemical studies of the dense part of D'Orbigny suggest that this rock underwent rapid, complete crystallization (Mittlefehldt et al., 2001, 2002). As shown by Mittlefehldt et al. (2002), D'Orbigny cannot be made by a single melt but needs a hybrid origin with a second melt having been successively added in proper doses during the final phases of rock formation. However, this igneous genetic model seems to fail when the porous and the dense parts of D'Orbigny are taken into consideration. D'Orbigny is peculiar in several respects, prompting Kurat et al. $(2001 \mathrm{a}, \mathrm{b})$ to consider a nonigneous origin for this rock.

One of the unusual features of D'Orbigny is the abundant presence of glass, a phase that has not been previously reported from any other angrite (Varela et al., 2001a). This feature makes D'Orbigny a unique member of the angrite group.

Besides a major and trace element study of the different types of glasses in this meteorite, we report on the peculiar way these glasses occur. This study aspires to shed light on the mechanism of formation of glasses helping to arrive at an improved view on angrite genesis.

Preliminary reports on glasses from D'Orbigny have been presented at the 32nd Lunar and Planetary Science Conference in Houston, Texas, and the 64th Annual Meeting of the Meteoritical Society in Vatican City, Rome, Italy (Varela, et al., 2001a,b).

\section{ANALYTICAL TECHNIQUES}

Major chemical compositions of glasses were obtained using an ARL-SEMQ microprobe, a JEOL 6400 scanning electron microscope (NHM, Vienna), and a SX100 Cameca electron microprobe (Institute of Petrology, University of Vienna). Microprobe analyses were performed at $15 \mathrm{kV}$ acceleration potential and $10 \mathrm{nA}$ sample current; the counting time for all elements was $10 \mathrm{~s}$. A Nonius KappaCCD diffractometer (Institute of Mineralogy and Crystallography, University of Vienna) was used to verify the amorphous nature of some of our samples. Glasses were analyzed for their trace element contents using the laser ablation inductively coupled plasma mass spectrometry (LAICP-MS) facility at Memorial University of Newfoundland. The instrument is a VG PlasmaQuad 2S + ICP-MS coupled to an in-house built 266-nm NdYAG laser. The ICP-MS instrument is equipped with a fast-switching quadrupole mass filter and a single Galileo-type electron multiplier. The laser beam is focused through the objective of a microscope onto the sample surface. A $50 \mathrm{~cm}^{3}$ sample cell is mounted on the microscope via a computer-driven motorized stage of the microscope. The laser was set up to produce an energy of $1.5 \mathrm{~mJ} / \mathrm{pulse}$ (measured just before the beam entered the objective of the microscope) at a repetition rate of $10 \mathrm{~Hz}$ with the laser beam into a spot 200 $\mu \mathrm{m}$ above the surface of the sample. The cell was flushed with He gas during ablation to minimize fall-back of ejecta and thus maximize analytical sensitivity. Typical data acquisitions consisted of a 60-s measurement of the gas blank before the start of ablation, which lasted another $60 \mathrm{~s}$. Laser ablation produced an $\sim 50-\mu \mathrm{m}$-wide and $60-\mu \mathrm{m}$ deep pit in the sample. Data were acquired in time-resolved-peakjumping-pulse-counting mode with 1 point measured per peak for each of 28 masses of the elements of interest. Quadrupole settling time was $1 \mathrm{~ms}$ and the dwell time was $8.3 \mathrm{~ms}$ on each mass.

Raw ICP-MS data were corrected for electron multiplier dead time $(20 \mathrm{~ns})$ and processed offline using a spreadsheet program (LAMTRACE, S. Jackson, unpublished) to integrate signals, subtract the gas blank, and calculate concentrations. Samples were calibrated against the NIST SRM 612 standard using the concentration values of Pearce et al. (1997). Silicon, determined by Electron Microb-Probe (EMP) analysis, was used as the internal standard. United States Geological Survey (USGS) reference silicate glass BCR-2G was analyzed 19 times as a secondary standard to check accuracy and precision of the technique over a month-long period that included this study. The measurements for most elements agree, within $8 \%$, with the preferred values determined previously for BCR2-G by solution ICP-MS at Memorial University (unpublished data). Exceptions are $\mathrm{Li}(-12 \%), \mathrm{Ti}$ $(+18 \%)$, and $\mathrm{Cr}(+16 \%)$. The high Ti results may reflect an overestimate of the Ti concentration in NIST 612 by Pearce et al. (1997). The $\mathrm{Cr}$ determinations are compromised by spectral interferences at the low levels of $\mathrm{Cr}$ in BCR-2G but are expected to be much more accurate at the high levels present in the D'Orbigny glasses. Long-term precision, defined as the relation standard deviation of the mean of the 19 BCR2-G analyses performed during this study, is $12 \%$ or better for all elements except $\mathrm{Cr}(17 \%)$ and $\mathrm{Tm}(14 \%)$. Trace element analyses of glasses of glass inclusions and glass pockets were made with the Cameca IMS $3 \mathrm{~F}$ ion microprobe at Washington University, St. Louis, following a modified procedure of Zinner and Crozaz (1986). Carbon and nitrogen measurements in glass inclusions were carried out at the nuclear microprobe facilities of Pierre Süe laboratory (Saclay, France) by using the ${ }^{12} \mathrm{C}(\mathrm{d}, \mathrm{p}){ }^{13} \mathrm{C}$ and ${ }^{14} \mathrm{~N}(\mathrm{~d}, \mathrm{p}){ }^{15} \mathrm{~N}$ nuclear reactions, respectively. The analyses were performed with a $5 \times 5 \mu \mathrm{m}^{2}$ beam size. The detection limits of $\mathrm{C}$ and $\mathrm{N}$ in glasses were calculated to be 45 and 10 ppm, respectively. To test the validity of measurements, carbon and nitrogen were measured against standard glasses. The error was estimated to be $\sim 5 \%$. For details in the application of the nuclear reaction technique for carbon and nitrogen analyses, see Varela et al. (2000, 2003).

\section{RESULTS}

The investigated samples are: PTS "D'Orbigny B" and "D'Orbigny C," and different types of glasses separated from rock specimens and rock debris: "D'Orbigny B2": containing glass samples CC1, HH1, AA2, C and the "MF2" containing low-field magnetic separates (all from NHM, Vienna).

\subsection{Glass Occurrences}

Glasses in the D'Orbigny angrite occur in the following modes:

1. Glass filling in part open druse space with free surfaces forming menisci (Fig. 1A,B). The most common glass fills former open spaces, is black (brown in transmitted light) with brilliant luster and conchoidal fractures. It can be dense (named glass patches) (Fig. 1C), containing only a few bubbles, or foamy (named glass with bubbles), with all possible transitions, even over short distances (Fig. 1D). Dense glasses in some cases also coat olivines and augites inside open druses (Fig. 2A).

2. Glass filling some of the abundant hollow shells (named glass sphere) (Fig. 2B,C). One of these glass spheres was cut into five slices. These glasses show dark-light schlieren in transmitted light that resemble flow lines that roughly follow the spherical outlines (Fig. 2D). However, the associated bubbles are always perfectly round (Fig. 3A). The surface of the glasses that fill the hollow shells replicates the inner side of the shell (Fig. 3B). Glasses occasionally contain rounded mineral and-rarely-rock fragments (Figs. 2D, 3A); some contain small dendrites of olivine and/or magnetite. Small (1-50 $\mu \mathrm{m})$ sulphide blebs (Ni-bearing pyrrhotite) associated with small bubbles are common. Sometimes two sulfides 
A

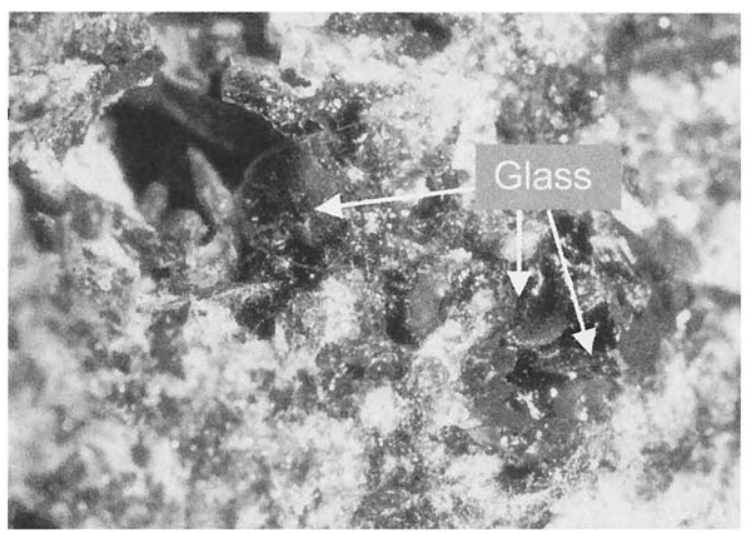

C

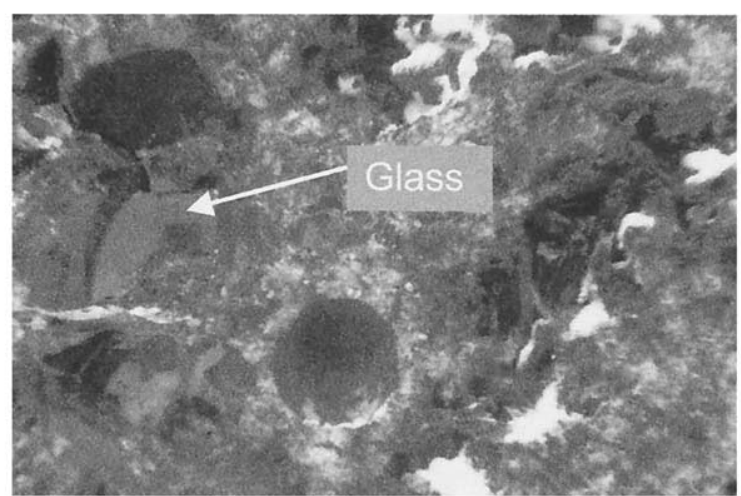

B

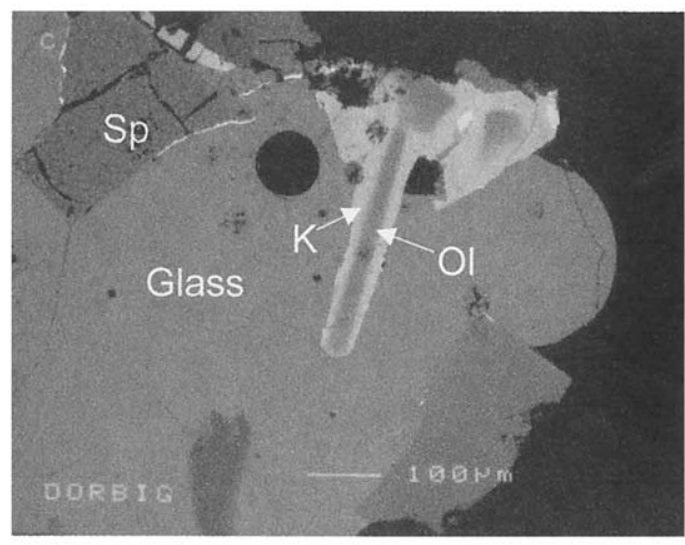

D

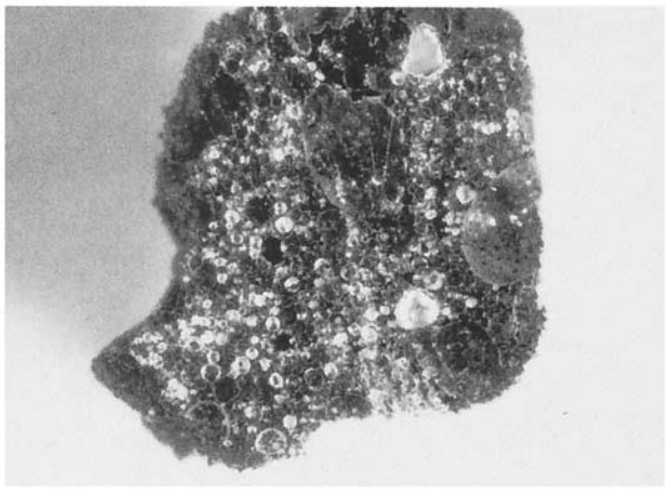

Fig. 1. Glasses in the D'Orbigny angrite. (A) Glass (black) filling open druse (width of picture is $0.5 \mathrm{~cm}$ ). (B) Back-Scattered Electron (BSE) image of glass filling open druse. Note that the free surface forms a meniscus and that glass includes an olivine covered by kirschsteinite. Conversion of olivine (Ol) (gray) to kirschsteinite (K) (light gray) decreases in volume with distance into the glass (from upper center to center). Also present are anorthite (gray), sulfide (white), and bubbles (black) of different sizes. (C) Coarse-grained specimen showing glass (center, left), a hollow sphere (lower center), and a druse (right) (width of picture is $1 \mathrm{~cm}$ ). (D) Foamy glass (width of picture is $0.5 \mathrm{~cm}$ ).

coexist with the Ni-rich one forming a corona decorating the surface of the bleb (Fig. 3C).

In the following paragraphs we make the following distinction between two types of glasses hosted in olivines: Primary glass inclusions have smooth shapes (round or ellipsoidal) with a shrinkage bubble. Occasionally they can have, in addition, several crystals and in this case we name it multiphase inclusion. Glass pockets are irregularly shaped, bubble-free glasses.

3. Glass inclusions in olivines were observed in the PTS sample D'Orbigny (B) (glass inclusions 1, 3, 5, and 6) and in olivines from low-field magnetic separates, sample MF2 (glass inclusions A, B, C, and D). Primary glass inclusions in olivine (Fig. 4A) have sizes up to $20 \mu \mathrm{m}$ and consist of glass and a shrinkage bubble, with some of them also containing a sulphide globule (Ni-free). Only one multiphase inclusion was encountered; it contains in addition to glass an olivine crystal, three (anhedral and euhedral) pyroxene crystals, and a bubble (Fig. 4B). None of the analyzed glass inclusions, with the exception of glass inclusion
1 , are reached by fractures. Glass inclusions are located in the center of the olivine (Fig. 4C encircled area) or near the surface. They occur isolated or form clusters or decorate growth zones (Fig. 4C, white arrows). In the latter case, the glass of the glass inclusions is generally devitrified (Fig. 4C, inset). Also, the devitrified glasses are present in those inclusions that are reached by fractures. An example is shown in Figure 5A, where for two inclusions hosted by the same olivine, the inclusion that is fracture-free (lower right corner) has a transparent glass, whereas in that reached by a fracture (upper left corner) the glass is devitrified (Fig. 5A, inset).

4. Glass pockets in olivine (encircled areas in Fig. 5B) are present in olivines that also contain glass inclusions (white arrow in Fig. 5B). They exclusively consist of glass, contain no bubbles, and fill irregular spaces. All glass pockets have a halo enriched in FeO (light gray shade in figure). This feature is absent from glass inclusions. Glasses pockets, as well as the glass inclusions, were observed in the dense portion of D'Orbigny, characterized by a subophitic micro- 
A

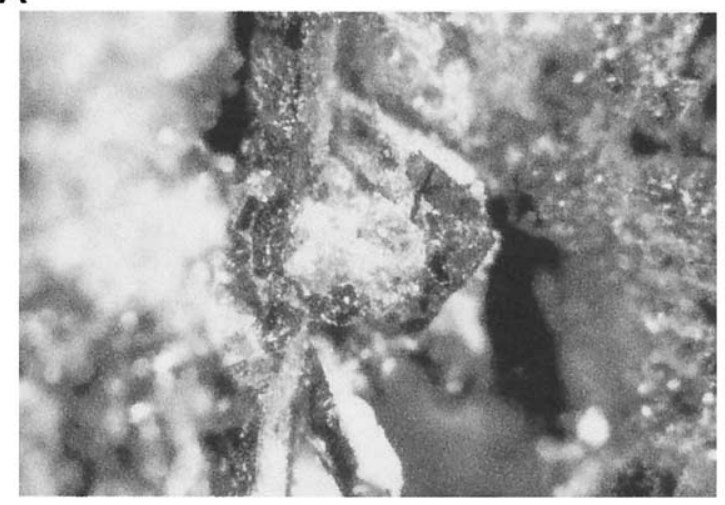

C

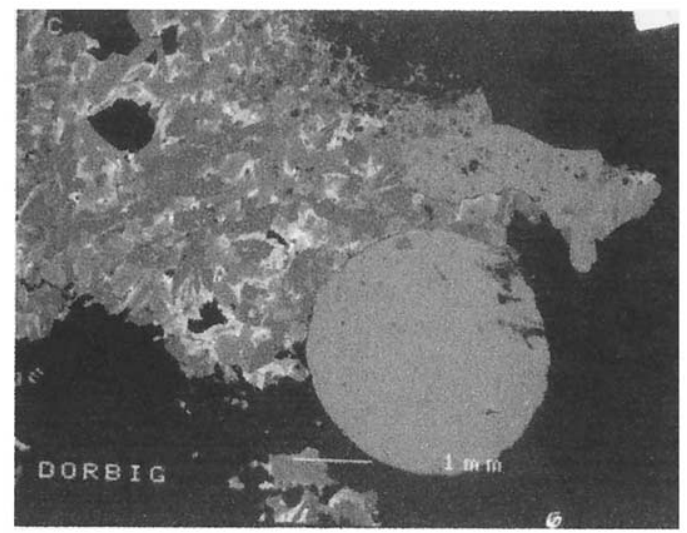

B

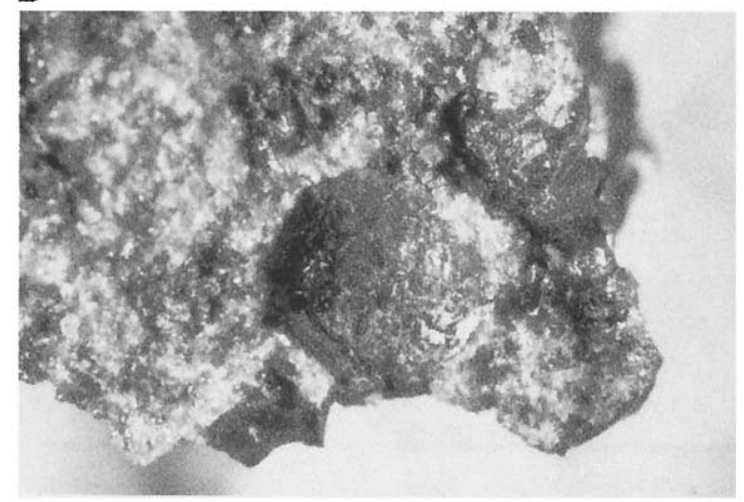

D

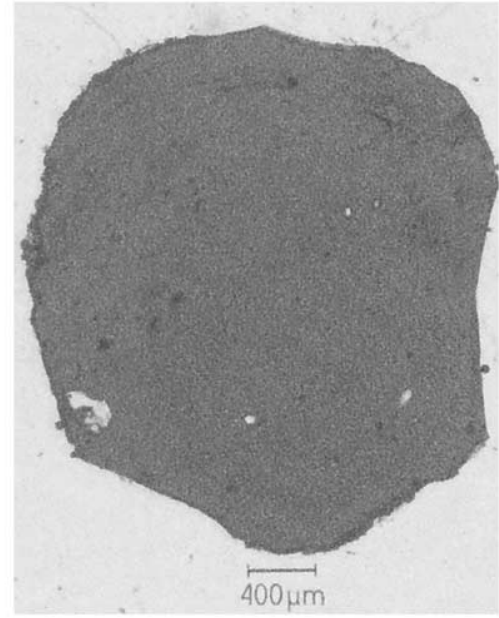

Fig. 2. Glasses in the D'Orbigny angrite. (A) Glass (black) in druse covering an olivine (center) (width of picture is 0.3 $\mathrm{cm}$ ). (B) Glass filling a hollow sphere; note the botryoidal surface - a replicate of the botryoidal surface of the originally solid sphere (width of picture is $6 \mathrm{~mm}$ ). (C) BSE image of glass filling a hollow sphere and a glass patch. The glass appears chemical homogeneous but contains variable amounts of mineral grains (mainly anorthite). (D) Transmitted light image of a glass sphere. Note schlieren and relic minerals (white).

gabbroic texture. For detailed petrographic description of D'Orbigny see Kurat et al. (2001a,b,c), Mittlefehldt et al. (2002), and Kurat et al. (2002).

The sizes of glasses vary from tens of $\mu \mathrm{m}$ (glass inclusions) to several $\mathrm{mm}$ (in druses and spheres). An X-ray test of a representative sample of druse-filling glass revealed glass fringes only.

\subsection{Chemical Composition of Glasses and Olivines}

\subsubsection{Major element content of glasses}

The chemical compositions of glasses of glass inclusions (which in the following we shall call inclusion glass), of glass pockets (GP), glass patches, glass with bubbles (GWB), and glass spheres (GS) are given in Table 1. The major element composition of glasses varies as follows:

Inclusion glasses comprise clearly two groups: Group A (including glass inclusions 6, 5, 3, and 1) glasses have low $\mathrm{FeO}$ (9.3 wt.\% to $13.2 \mathrm{wt}$ ) and high $\mathrm{Al}_{2} \mathrm{O}_{3}$ (17.5 to 21.7 wt.\%) contents, with $\mathrm{MgO}$ contents varying from 1.5 to $5.7 \mathrm{wt} . \%$ and that of $\mathrm{CaO}$ from 21.2 to 23.3 wt.\% (Figs. 6 and 7). Group $B$ (consisting of glass inclusions $\mathrm{A}, \mathrm{B}, \mathrm{C}$, and $\mathrm{D}$ ) glasses have $\mathrm{Al}_{2} \mathrm{O}_{3}$ contents that are about half (from 9.3 to $12.8 \mathrm{wt} . \%$, Fig. 7) and $\mathrm{FeO}$ contents that are twice those of group A glasses (from 18.5 to 23.8 wt.\%), whereas their $\mathrm{MgO}$ (3.1 to $6.1 \mathrm{wt} . \%$ ) and $\mathrm{CaO}$ (18.5 to 20.4 wt.\%) contents are comparable to those of group A glasses (Fig. 6).

The mean chemical composition of glass from the glass pockets (Table 1, GP (16)) is within the range of all other glasses. However, some of the major element contents can vary widely like, for example, $\mathrm{Al}_{2} \mathrm{O}_{3}$ between 14.4 and $5.8 \mathrm{wt} . \%$ and $\mathrm{TiO}_{2}$ between 1.52 and $4.1 \mathrm{wt} . \%$ in glass pocket $6_{\mathrm{a}-\mathrm{c}}$ and glass pocket $6_{\mathrm{d}-\mathrm{g}}$, respectively (Table 1 and Fig. 8). Glass pockets $6_{\mathrm{a}-\mathrm{c}}$ and $6_{\mathrm{d}-\mathrm{g}}$, as well as $5_{\mathrm{a}-\mathrm{b}}$ and $5_{\mathrm{c}-\mathrm{e}}$ are both hosted by single olivines. Note that glass pocket $6_{\mathrm{a}-\mathrm{c}}$ is crosscut by a fracture (Fig. 5B).

The chemical composition of all other glasses (glass patches, glass with bubbles [GWB], and glass spheres [GS]) varies 
A

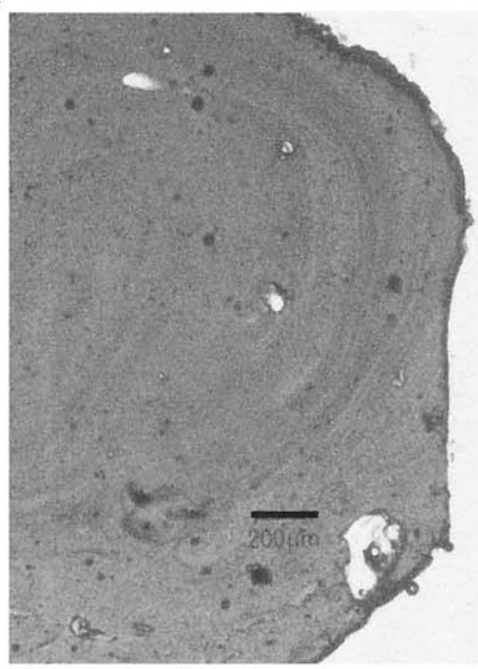

B

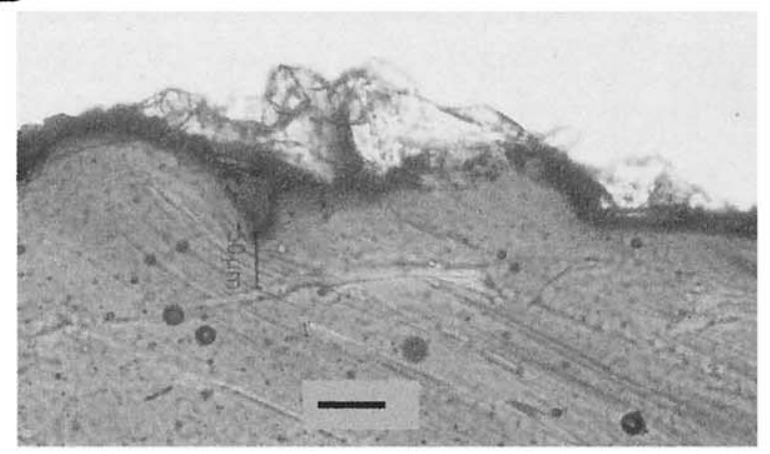

C

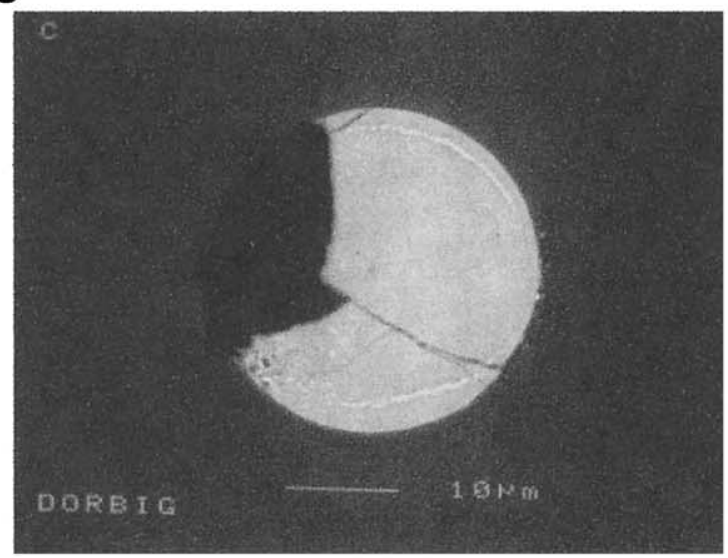

Fig. 3. Close-ups of glasses in the D'Orbigny angrite. (A) A detail of glass from Figure 2D showing the well-developed flow lines that follow the surface and spherical bubbles. Transmitted light picture. (B) Detail transmitted light image of the glass sphere shown in Figures 2D and $3 \mathrm{~A}$ showing schlieren, bubbles, and residual material from the shell. Note that the indentation near the scale possibly marks a grain boundary of the phase that originally formed the sphere. Length of the scale bar: $50 \mu \mathrm{m}$. (C) BSE image of an Fe sulfide sphere in glass from Figure $2 \mathrm{C}$ showing Ni-rich sulfide forming a corona decorating the surface of the sphere.
A

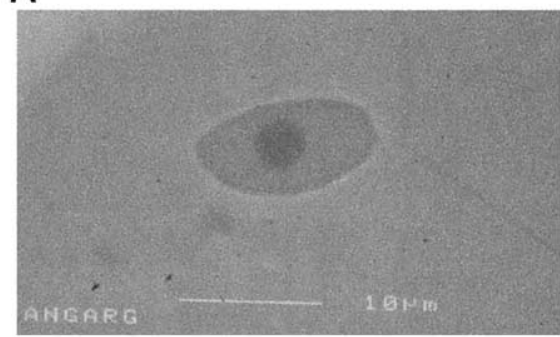

B

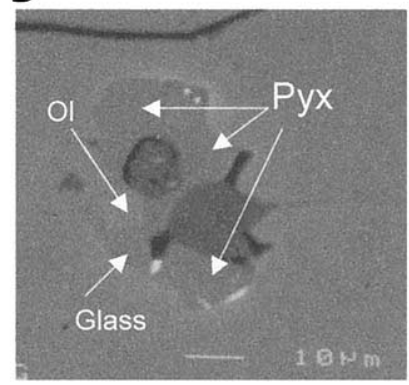

C

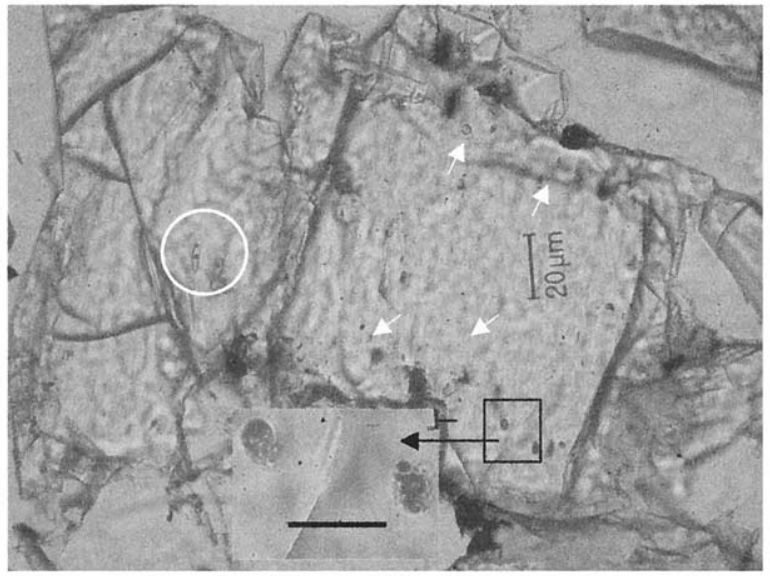

Fig. 4. Glass-bearing inclusions in D'Orbigny olivine. (A) BSE image of a glass inclusion (glass 5) with bubble. (B) BSE image of the only multiphase inclusion found in olivine showing an olivine crystal (Ol), anhedral and euhedral pyroxenes (Pyx), glass (gray), an irregular cavity and a bubble. (C) Transmitted light image of an olivine showing an isolated clear glass inclusion (glass 3 ) in the center (encircled) and devitrified glass inclusions forming part of the border zone (white arrows). The inset (scale bar: $10 \mu \mathrm{m}$ ) shows a detail of the devitrified inclusions.

within narrow limits: $\mathrm{SiO}_{2}$ (37.2 to $41.1 \mathrm{wt} \%$ ); $\mathrm{TiO}_{2}$ (0.5 to 1.04 wt. \%); $\mathrm{Al}_{2} \mathrm{O}_{3}$ (11.9 to 13.2 wt.\%); $\mathrm{FeO}$ (23.2 to 25.9 wt. $\%) ; \mathrm{MnO}(0.24$ to 0.36 wt. $\%)$; $\mathrm{MgO}$ (6.6 to $8.0 \mathrm{wt} . \%)$; and $\mathrm{CaO}$ (13.6 to 16.5 wt.\%) (Table 1$)$.

\subsubsection{Carbon and nitrogen contents of glasses}

Four glass inclusions were analyzed for carbon and nitrogen, and contents varying from 40 to $735 \mathrm{ppm} \mathrm{C}$ and from below the detection limit $(<10 \mathrm{ppm})$ to $180 \mathrm{ppm} \mathrm{N}$ were found. In a glass 


\section{A}

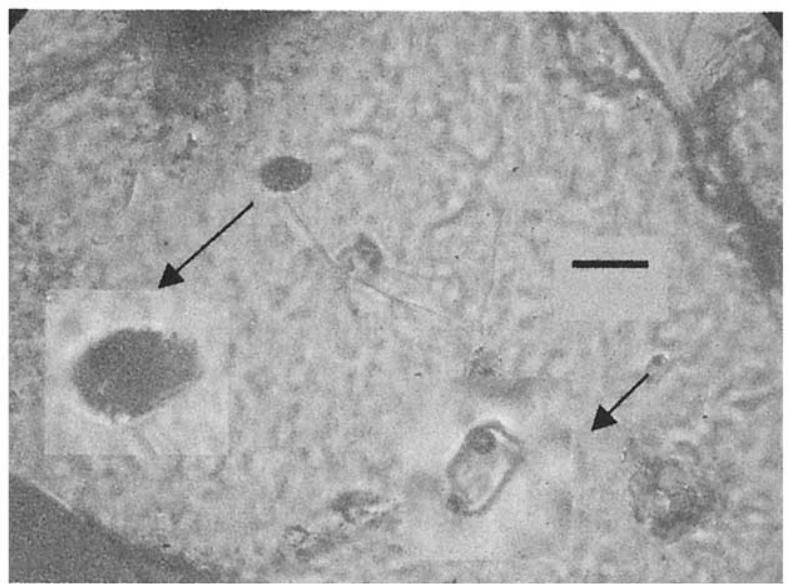

B

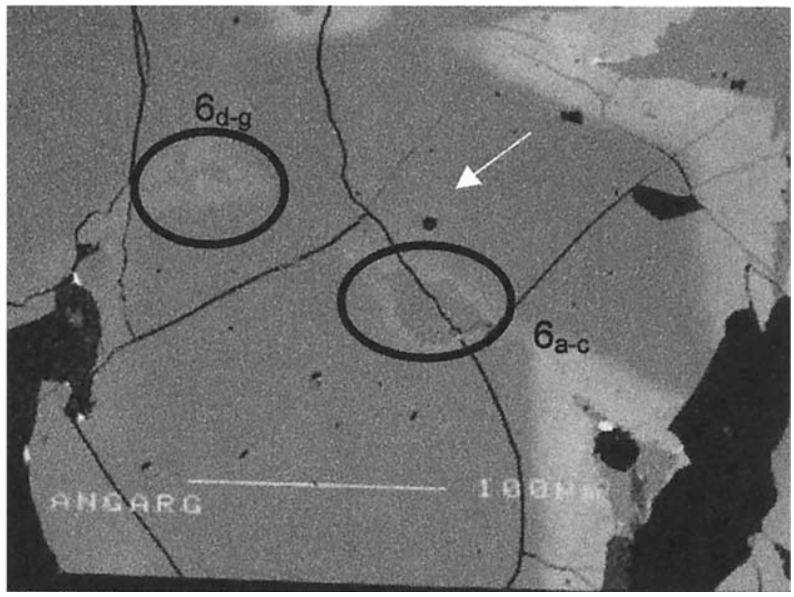

Fig. 5. Glass inclusions and glass pockets in D'Orbigny olivine. (A) Transmitted light image of an olivine with two glass inclusions. The glass inclusion that is not reached by a fracture (right lower corner, 10 $\mu \mathrm{m}$ in size) has a transparent glass while the one reached by a fracture (left upper corner, $15 \mu \mathrm{m}$ in size) has devitrified glass. Scale bar: 20 $\mu \mathrm{m}$. Insets show details of both glasses. (B) BSE image of glass pockets 6a-c and 6d-g (encircled areas) and glass inclusion (glass 6, white arrow) in a single olivine crystal. Note the halo around the glass pockets that is caused by enrichment in $\mathrm{Fe}$ of the surrounding olivine over the bulk olivine. Light gray zones covering the surface of the olivine are made of Fe-, Ca-rich olivine and kirschsteinite.

sphere, a profile performed from center to the surface gave throughout carbon and nitrogen contents below the detection limit. The same results were obtained for glass patches and for a foamy glass (Table 1).

\subsubsection{Trace element contents of glasses}

All glasses are rich in trace elements. Cosmochemically refractory elements, including the REE, in glasses filling voids and shells and glass patches have a flat abundance pattern at $\sim 10 \times \mathrm{CI}$ abundances. Lithium, V $(\sim 1-3 \times \mathrm{CI}), \mathrm{Mn}(\sim 0.9$ $\times \mathrm{CI}), \mathrm{Cr}(\sim 0.1 \times \mathrm{CI})$, and $\mathrm{Co}, \mathrm{Ni}, \mathrm{Cu}$, and $\mathrm{Zn}($ all $<0.1 \times$ CI) (Figs. 9-11, and Tables 2, 3, and 4) contents are low. However, Sc is depleted with respect to the other refractory elements.

Trace element contents of inclusion glasses have also a flat abundance pattern at $10 \times \mathrm{CI}$ abundances and low contents of $\mathrm{Li}(\sim 2$ to $7 \times \mathrm{CI}), \mathrm{V}(\sim 1$ to $2 \times \mathrm{CI}), \mathrm{Mn}(\sim 2 \times \mathrm{CI})$, and $\mathrm{Cr}(\sim 0.2 \times \mathrm{CI})$, (Fig. 10, Table 4). Scandium has the same normalized abundance as all other refractory elements, and $\mathrm{Sr}$ and $\mathrm{Be}$ are almost as abundant $(7-9 \times \mathrm{CI})$, except in glass 1 , which is depleted in these elements and which has also a slightly fractionated REE pattern with $\mathrm{La}_{\mathrm{N}}<\mathrm{Lu}_{\mathrm{N}}\left(\mathrm{La}_{\mathrm{N}}, \mathrm{Lu}_{\mathrm{N}}\right.$ : CI-normalized abundance).

Trace elements in glass pockets show also relative flat abundance patterns between 10-20 × CI abundances. All patterns have a small negative Eu anomaly and slight depletions in Sc, $\mathrm{Sr}$, and $\mathrm{B}$ contents with respect to the other refractory elements (Fig. 11). Glass in GP $5_{\mathrm{a}-\mathrm{b}}$ has $\mathrm{La}_{\mathrm{N}}<\mathrm{Lu}_{\mathrm{N}}$ and is poor in $\mathrm{Sr}, \mathrm{Be}$, and $\mathrm{Nb}$ but rich in $\mathrm{Sc}, \mathrm{Ti}$, and $\mathrm{Zr}$. Abundances of $\mathrm{V}, \mathrm{Cr}, \mathrm{Mn}, \mathrm{Li}$, and $\mathrm{Rb}$ in glass pockets are similar to those in glasses of glass inclusions (Figs. 10 and 11; Tables 3 and 4).

\subsubsection{Major and trace element contents of olivine}

The $\mathrm{FeO}$ and $\mathrm{MgO}$ contents of the host olivines of glass inclusions vary from 31.1 to $41 \mathrm{wt} . \%$ and from 32.1 to 23.6 wt.\%, respectively (Table 1 ).

Trace element contents of olivines hosting glass inclusions vary widely (Fig. 10). Hosts 3 and 6 have highly fractionated abundances with the highly incompatible elements being strongly depleted (e.g., $\mathrm{La}_{\mathrm{N}} \sim 0.006 \times \mathrm{CI}$ ). Host 5 is much richer in trace elements than the former $\left(\mathrm{La}_{\mathrm{N}} \sim 0.2 \times \mathrm{CI}\right)$ and Host 1 is very rich in trace elements $\left(\mathrm{La}_{\mathrm{N}} \sim 3.5 \times \mathrm{CI}\right)$ and has an almost flat abundance pattern. The $\mathrm{Sc}$ abundance is generally $\sim 3 \times \mathrm{CI}$ in all olivines but the $\mathrm{Lu}$ abundance varies from $\sim 1 \times \mathrm{CI}$ (host 3 and 6 ) to $\sim 6 \times \mathrm{CI}$ (host 1). Iron, Mn, and Li abundances are high $(\sim 2 \times 2.5 \times$ and $\sim 6 \times \mathrm{CI}$, respectively) and those of $\mathrm{V}$ and $\mathrm{Cr}$ are low $(\sim 0.6 \times$ and $0.2 \times \mathrm{CI}$, respectively).

\section{DISCUSSION}

Angrites are widely believed to be igneous rocks of basaltic composition (Mittlefehldt and Lindstrom, 1990). Nevertheless, they have many primitive features and a possible origin as crystallized melts directly related to fractionated or unfractionated nebular components have also been considered (Prinz et al., 1988, 1990; Prinz and Weisberg, 1995; Longhi, 1999). Furthermore, there are indications that angrites derived directly from the solar nebula (Kurat et al., 2002).

Here, we will focus our discussion on the petrographic characteristics and chemical composition (major and trace element) of the divers types of glasses present in D'Orbigny. These results are confronted with existing genetic models of angrites with the aim to shed some light on the genesis of these rocks.

\subsection{Glass Formation by Igneous Processes: Arguments For and Against}

According to Mittlefehldt et al. (2002), D’Orbigny is an unshocked, unmetamorphosed, vesicular igneous rock that un- 
Table 1. Major element contents (wt.\%) of glasses in the D'Orbigny angrite (EMP data) and C and $\mathrm{N}$ content (ppm) of glass inclusions.

\begin{tabular}{|c|c|c|c|c|c|c|c|c|c|c|c|c|c|c|c|c|c|c|c|c|c|}
\hline \multirow[b]{3}{*}{ Sample } & \multicolumn{8}{|c|}{ Glass inclusions in olivine } & & & & & & & & & & & & & \\
\hline & \multicolumn{4}{|c|}{ A } & \multicolumn{4}{|c|}{ B } & \multicolumn{5}{|c|}{ GP } & \multicolumn{4}{|c|}{ Glass Patches } & \multicolumn{4}{|c|}{ GS } \\
\hline & $6^{*}$ & $3 *$ & $5^{*}$ & $1^{*}$ & $\mathrm{D}$ & B & A & $\mathrm{C}$ & Aver. & $6_{\mathrm{a}-\mathrm{c}}$ & $6_{\mathrm{d}-\mathrm{g}}$ & $5_{\mathrm{a}-\mathrm{b}}$ & $5_{\mathrm{c}-\mathrm{e}}$ & & & & Aver. & GWB & $\mathrm{T} 1$ & S2 & S1 \\
\hline Number & & & & & & & & & 16 & 3 & 4 & 3 & 3 & & & & 15 & & 15 & 10 & 10 \\
\hline $\mathrm{SiO}_{2}$ & 41.7 & 42.6 & 41.9 & 41.3 & 40.1 & 41.1 & 39.6 & 40.3 & 40.6 & 41.3 & 42.6 & 40.7 & 43.0 & 40.2 & 41.1 & 40.7 & 39.8 & 37.2 & 39.7 & 39.9 & 40.4 \\
\hline $\mathrm{TiO}_{2}$ & 1.67 & 1.43 & 1.50 & 1.45 & 1.34 & 1.80 & 2.00 & 1.91 & 2.42 & 1.52 & 4.10 & 1.98 & 2.35 & 0.83 & 0.81 & 1.04 & 0.50 & 0.50 & 0.85 & 0.84 & 0.82 \\
\hline $\mathrm{Al}_{2} \mathrm{O}_{3}$ & 19.6 & 21.7 & 21.7 & 17.5 & 12.2 & 12.8 & 11.3 & 9.8 & 12.3 & 14.4 & 5.8 & 15.1 & 9.7 & 13.1 & 13.2 & 12.5 & 12.9 & 11.9 & 12.1 & 12.7 & 12.3 \\
\hline $\mathrm{Cr}_{2} \mathrm{O}_{3}$ & 0.04 & 0.04 & 0.09 & 0.04 & 0.05 & 0.05 & 0.13 & 0.05 & 0.09 & 0.03 & 0.08 & 0.10 & 0.14 & 0.07 & 0.16 & 0.05 & 0.07 & 0.00 & 0.08 & 0.08 & 0.08 \\
\hline $\mathrm{FeO}$ & 11.0 & 9.3 & 10.2 & 13.2 & 20.9 & 18.5 & 23.8 & 20.6 & 18.8 & 17.5 & 19.3 & 16.6 & 16.4 & 23.3 & 23.2 & 24.5 & 23.8 & 25.9 & 24.4 & 24.0 & 25.3 \\
\hline $\mathrm{MnO}$ & 0.16 & 0.12 & 0.10 & 0.18 & 0.26 & 0.25 & 0.27 & 0.19 & 0.21 & 0.19 & 0.22 & 0.20 & 0.17 & 0.36 & 0.25 & 0.28 & 0.27 & 0.34 & 0.25 & 0.24 & 0.27 \\
\hline $\mathrm{MgO}$ & 1.87 & 2.31 & 1.53 & 5.73 & 5.6 & 6.10 & 3.10 & 5.1 & 4.27 & 3.61 & 4.44 & 4.39 & 5.7 & 7.5 & 7.7 & 7.5 & 7.6 & 6.6 & 7.8 & 7.3 & 8.0 \\
\hline $\mathrm{CaO}$ & 23.3 & 22.8 & 21.7 & 21.2 & 18.5 & 19.30 & 18.5 & 20.4 & 21.4 & 21.6 & 21.9 & 21.5 & 22.3 & 13.8 & 14.5 & 14.5 & 14.3 & 16.5 & 14.2 & 13.9 & 13.6 \\
\hline Total & 99.3 & 100.3 & 98.7 & 100.6 & 99.0 & 99.70 & 98.8 & 98.4 & 100.1 & 100.2 & 98.4 & 100.6 & 99.8 & 99.2 & 100.9 & 101.1 & 99.2 & 98.9 & 99.4 & 99.0 & 100.8 \\
\hline $\mathrm{C}$ ppm & 40 & & 64 & & 425 & 735 & & & & & & & & & & & & & & & \\
\hline $\mathrm{N}$ ppm & 180 & & 150 & & bd & bd & & & & & & & & & & & & bd & bd & & \\
\hline $\mathrm{FeO}$ Host & 35.5 & 32.5 & 41.0 & 31.1 & 34.8 & 33.0 & 38.0 & 38.2 & & & & & & & & & & & & & \\
\hline $\mathrm{CaO}$ Host & 1.19 & 0.91 & 1.64 & 0.91 & 1.00 & 0.90 & 1.20 & 1.47 & & & & & & & & & & & & & \\
\hline MgO Host & 27.3 & 31.0 & 23.6 & 32.1 & 26.5 & 29.3 & 25.3 & 26.3 & & & & & & & & & & & & & \\
\hline $\mathrm{Kd} \mathrm{Fe} / \mathrm{Mg}$ & 0.22 & 0.26 & 0.26 & 0.42 & 0.35 & 0.36 & 0.37 & 0.36 & & & & & & & & & & & & & \\
\hline \multicolumn{22}{|l|}{ CIPW-norm } \\
\hline $\mathrm{Pl}$ & 53.5 & 59.2 & 59.2 & 47.8 & 33.3 & 34.9 & 30.8 & 26.7 & 33.6 & 39.3 & 15.8 & 41.2 & 26.5 & 35.7 & 36.0 & 34.1 & 35.2 & 32.5 & 33.0 & 34.7 & 33.6 \\
\hline Di & 25.8 & 24.0 & 24.9 & 20.0 & 27.2 & 30.4 & 32.5 & 35.4 & 31.9 & 29.8 & 62.5 & 24.8 & 47.7 & 23.8 & 25.3 & 24.9 & 20.4 & 8.5 & 22.0 & 23.5 & 23.2 \\
\hline $\mathrm{Ol}$ & 6.9 & 6.3 & 5.6 & 19.6 & 27.6 & 23.4 & 24.1 & 22.3 & 19.0 & 17.8 & 6.2 & 19.4 & 12.4 & 36.5 & 36.0 & 37.4 & 38.9 & 44.8 & 39.1 & 37.1 & 40.3 \\
\hline $\mathrm{La}$ & 10.0 & 7.9 & 6.1 & 10.4 & 8.2 & 7.7 & 7.3 & 10.2 & 10.9 & 10.3 & 6.1 & 11.3 & 8.6 & 1.5 & 1.9 & 2.6 & 3.6 & 12.2 & 3.6 & 2.1 & 2.1 \\
\hline 11 & 3.2 & 2.7 & 2.8 & 2.8 & 2.5 & 3.4 & 3.8 & 3.6 & 4.6 & 2.9 & 7.8 & 3.8 & 4.5 & 1.6 & 1.5 & 1.9 & 0.9 & 0.9 & 1.6 & 1.6 & 1.6 \\
\hline
\end{tabular}

$\mathrm{GP}=$ glass pockets; GWB = glass with bubbles; GS = glass sphere; bd = below detection; Ti, $\mathrm{S} 1, \mathrm{~S} 2=$ Glass sphere profiles from center to border (mean of 15,10 , and 10 analyses, respectively); Ave $=$ Average.

* Glass inclusions analyzed by SIMS 


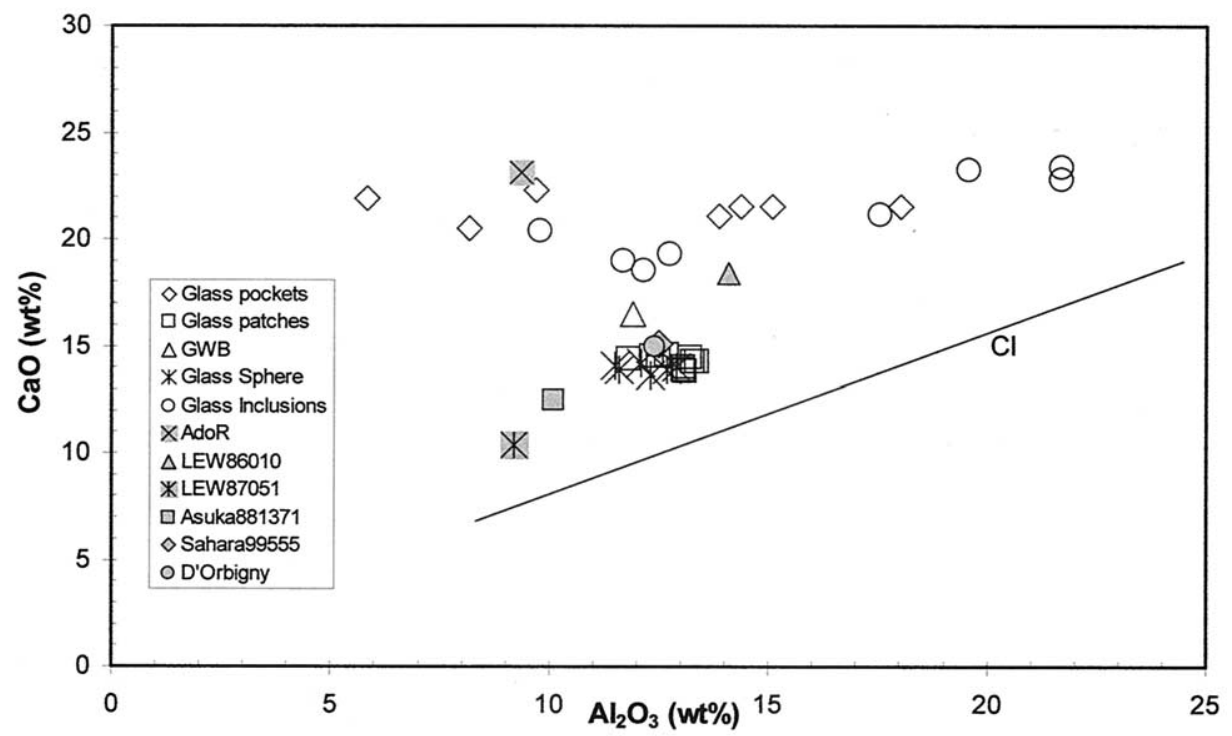

Fig. 6. $\mathrm{CaO}$ vs. $\mathrm{Al}_{2} \mathrm{O}_{3}$ diagram of all types of glasses in D'Orbigny. Compositions of glasses of glass patches and glass spheres tightly cluster around D'Orbigny bulk composition, whereas compositions of glass inclusions in olivine and of glass pockets are rich in $\mathrm{CaO}$ and vary widely in their $\mathrm{Al}_{2} \mathrm{O}_{3}$ contents. In this and in the following plots, angrites bulk rock, AdoR (Angra dos Reis), LEW 86010, LEW 87051, Asuka 881371, Sahara 99555, and D'Orbigny are given for comparison. CI is the $\mathrm{CaO} / \mathrm{Al}_{2} \mathrm{O}_{3}$ ratio of CI carbonaceous chondrites (Anders and Grevesse, 1989).

derwent rapid complete crystallization. The overall texture in their described samples is subophitic, with areas of graphic intergrowths of olivine + subcalcic kirschsteinite and anorthite. Their chip of rock lacks, unfortunately, all the features corresponding to the porous part of this meteorite, such as: the hollow spheres with well-developed shells of anorthite and olivine; the open druses with euhedral pyroxene crystals; the very large, isolated olivine crystals and polycrystalline olivinites; and the glasses.
Mittlefehldt et al. (2002) suggested that, although D'Orbigny represents a crystallized melt, this melt may have been of a hybrid composition and more than one melt may have been involved in the genesis of this rock.

However, the igneous model seems to fail in explaining the reverse zoning observed in olivine and augite. Mittlefehldt et al. (2002) indicate that they do not find a good mineralogical explanation for this reversal. Accordingly, they state: "There appears to be no obvious mineralogic control that can explain

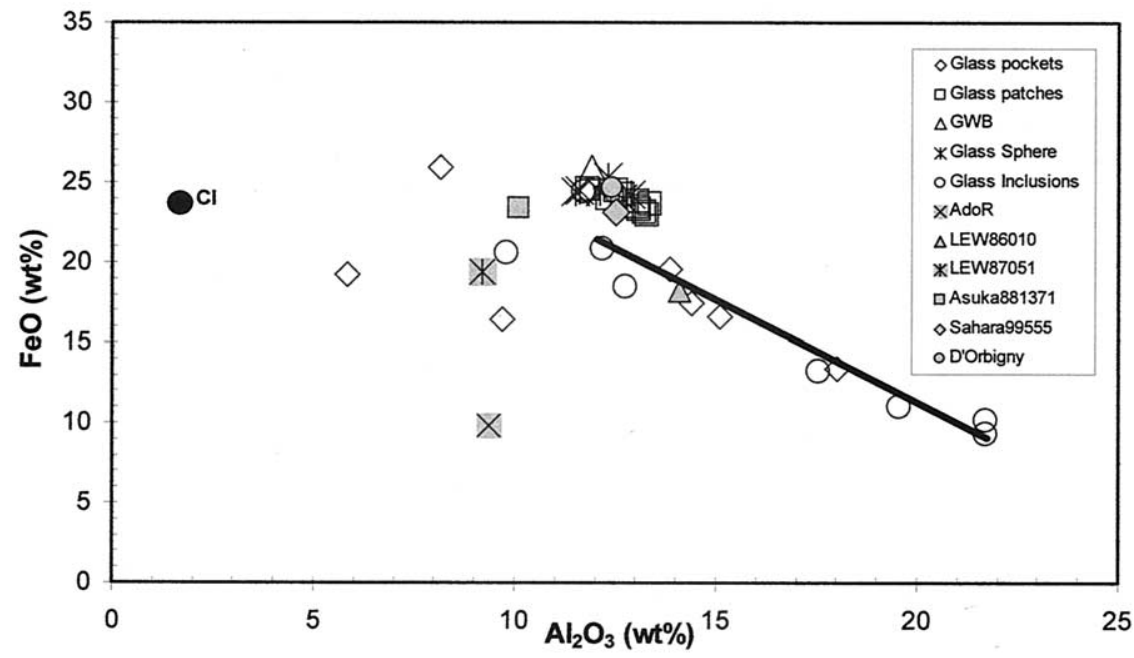

Fig. 7. $\mathrm{Al}_{2} \mathrm{O}_{3}$ vs. FeO diagram of all types of glasses in D'Orbigny. Note the anticorrelation shown by compositions of glass inclusions in olivine and of glass pockets. The correlation line through glass inclusions and some glass pockets $\left(\Delta \mathrm{FeO} / \Delta \mathrm{Al}_{2} \mathrm{O}_{3} \sim-1.4\right)$ seems to give evidence for an $\mathrm{Fe}-\mathrm{Al}$ exchange reaction (mole $\mathrm{FeO} / 1 / 2 \mathrm{~mol}^{2} \mathrm{Al}_{2} \mathrm{O}_{3}$ : 1.4). Compositions of glass patches and glass spheres cluster tightly around D'Orbigny bulk rock composition. The CI composition is shown for comparison. 


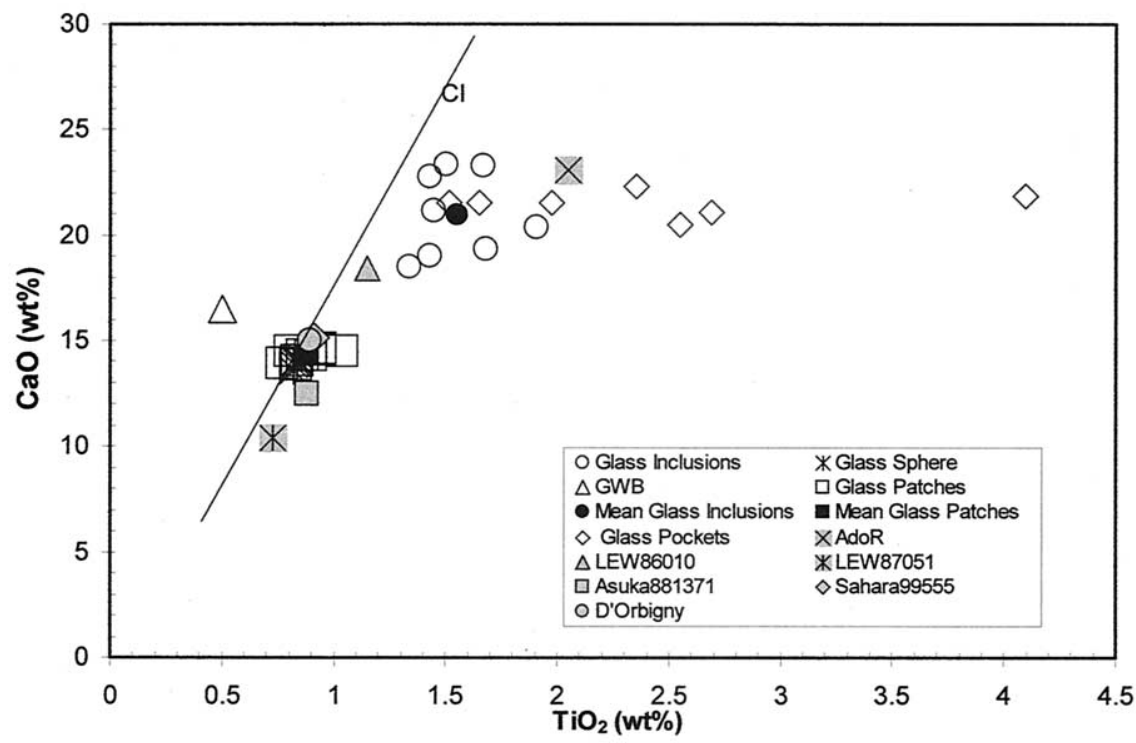

Fig. 8. $\mathrm{CaO}$ vs. $\mathrm{TiO}_{2}$ diagram of all types of glasses in D'Orbigny. Again, compositions of glass patches and glass spheres cluster tightly around the D'Orbigny bulk rock composition, whereas compositions of glass inclusions in olivine and of glass pockets in olivine are rich in $\mathrm{CaO}$ and have highly variable $\mathrm{TiO}_{2}$ contents.

these reversals, and we suggest that they were caused by additions of more primitive melt during the crystallization sequence." The petrographic evidence that lends support to their hypothesis seems to be provided by D'Orbigny glasses: "D'Orbigny contains glasses with compositions like the bulk rock composition (Vareta et al (2001), see Table 5) that must have entered the stone after crystallization." However, the observation and the study of all the pieces of D'Orbigny shows no interconnected glass veins crosscutting the rock, nor the well-known network of glasses that can be observed in many igneous rocks when glass has been injected or when glasses formed from melts created by different degrees of partial melt- ing that migrated along phases boundaries. This evidence indicate that glasses were not incorporated from an external source once the rock was formed but rather formed contemporaneously with the other phases.

The D'Orbigny glasses can very well represent melts from which angrites could have crystallized because olivine, augite, plagioclase, and larnite can be precipitated from them (CIPWnorm has An: Di: Ol 1: 1: 1). Some angrites such as LEW 87051 and Asuka 881371 appear to indeed have crystallized from a melt (Mikouchi et al., 1996; Yanai, 1994). The quench texture of LEW 87051 and its very low porosity strongly support this. The very abundant olivines, however, create a

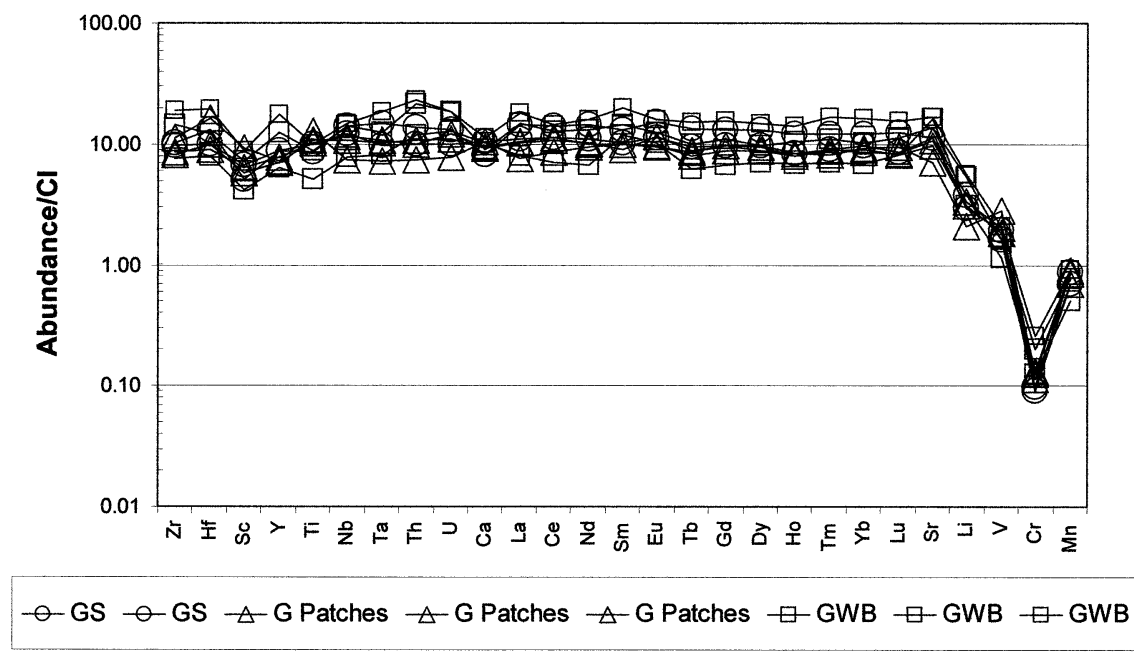

Fig. 9. CI-normalized trace element abundances in glass patches (G Patches), glass with bubbles (GWB), and glass spheres (GS) from D'Orbigny. ICP-MS data, Table 3. Elements in all plots are arranged in order of increasing volatility, except for the REE, which are arranged in order of increasing atomic number. $\mathrm{CI}$ abundances are from Anders and Grevesse (1989). 


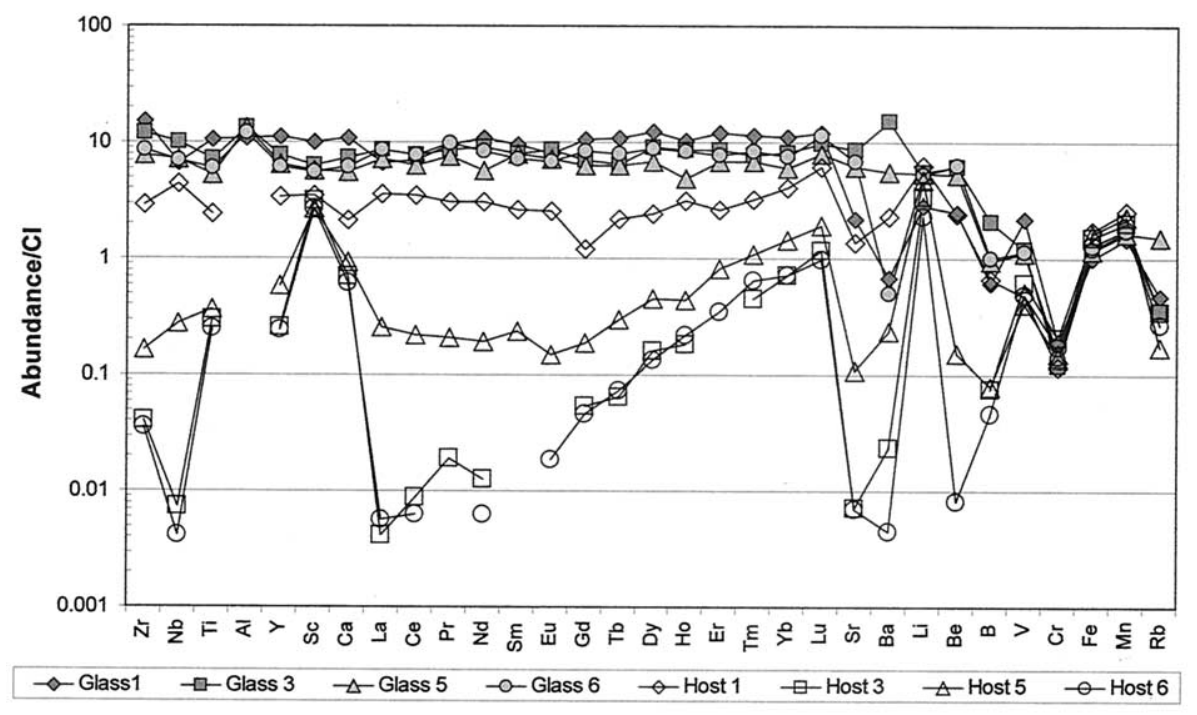

Fig. 10. CI-normalized trace element abundances in glasses of glass inclusions (Glass 1, 3, 5, and 6) and their host olivines (Host 1, 3, 5, and 6). SIMS data from Table 4.

problem and are considered to be xenocrysts (Prinz et al., 1990). Curiously, the melts from which the angrites with quench textures crystallized are all considered to be contaminated liquids of the angrite parent body (Mittlefehldt and Lindstrom, 1990; Mikouchi et al., 1996).

Several petrologic studies were done to find out if angrites could represent a melt composition or could be cumulate rocks from yet unknown basaltic melts. Treiman (1989) attempted to determine the composition of the melt from which Angra dos Reis, a pyroxenite angrite, could have crystallized and came up with a melt of a composition very similar to that of the bulk rock. However, this melt is not saturated in olivine and produces solely pyroxene but no olivine (which is present in appreciable amounts in Angra dos Reis). Also, the melting experiments of McKay et al. (1988) on compositions similar to that of LEW 86010 suggest that this angrite could have formed from a melt that had the chemical composition of the bulk rock. However, the modal composition of LEW 86010 could not perfectly be reproduced as it contains olivine and anorthite in excess of the experimental product. In their melting experiments, Jurewicz et al. (1993) investigated possible sources of angrite melts and found that minimum partial melts obtained from $\mathrm{CM}$ and $\mathrm{CV}$ chondrites under oxidizing conditions were angritic in composition and resembled the chemical composition of LEW 86010, except for the alkalis and some other elements.

D'Orbigny glasses are similar in composition to Asuka 881371 (a basaltic angrite) melt rock (Prinz and Weisberg, 1995) and to the meteorite specimen Ya 1154 (Yanai, 2000). Thus, melts of angritic composition exist, were commonly

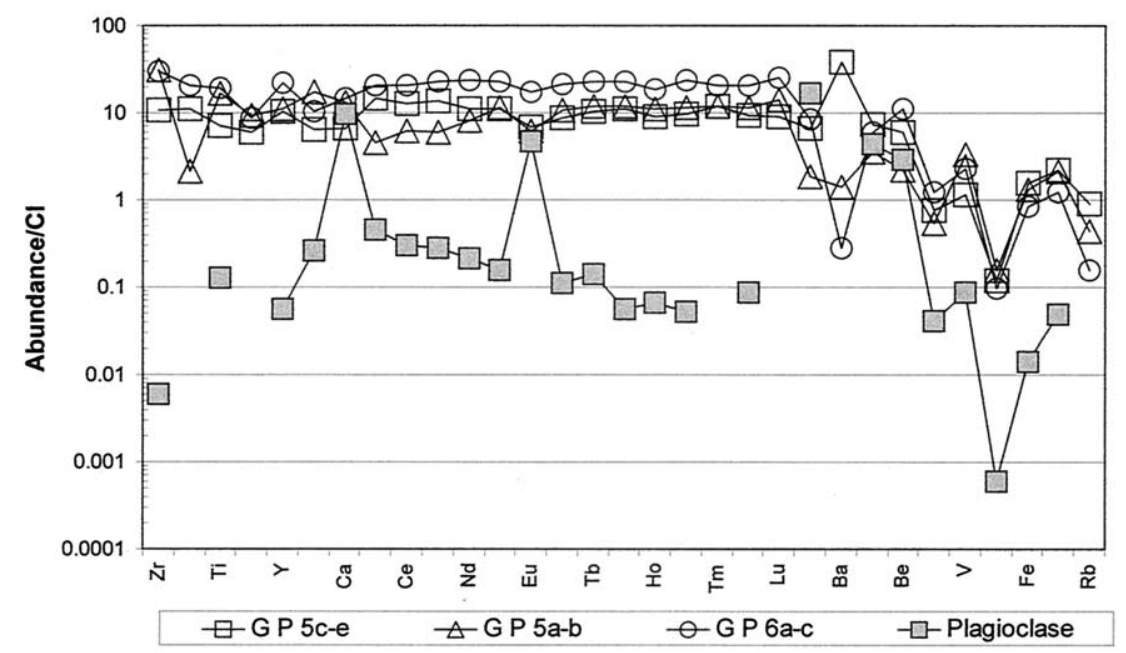

Fig. 11. CI-normalized trace element abundances in glasses of glass pockets 5a-b (GP 5a-b), 5c-e (GP 5c-e), 6a-c (GP 6a-c), and plagioclase. SIMS data from Table 4. 
Table 2. Trace element content (in ppm) of D'Orbigny ${ }^{\mathrm{a}}$ D'Orbigny glass, Asuka $881371^{\mathrm{b}}$ and LEW $870051^{\mathrm{b}}$.

\begin{tabular}{lccccc}
\hline & $\begin{array}{c}\text { D'Orbigny } \\
\text { Bulk }\end{array}$ & $\begin{array}{c}\text { Error } \\
(\%)\end{array}$ & $\begin{array}{c}\text { Glass } \\
\text { D'Orbigny }\end{array}$ & $\begin{array}{c}\text { Asuka } \\
881371\end{array}$ & $\begin{array}{c}\text { LEW } \\
\text { Den10051 }\end{array}$ \\
\hline $\mathrm{Ti}$ & 4600 & 15 & 5050 & & 5100 \\
$\mathrm{Sc}$ & 36 & 3 & 45 & 3209 & 42 \\
$\mathrm{Cr}$ & 300 & 5 & 330 & 950 & 1100 \\
$\mathrm{Co}$ & 33 & 5 & 30 & 51 & 28.5 \\
$\mathrm{Ni}$ & 28 & 20 & 72 & 114 & 45 \\
$\mathrm{Sr}$ & 120 & 20 & 70 & & 92 \\
$\mathrm{Zr}$ & 50 & 15 & 39 & 34 & \\
$\mathrm{La}$ & 2.8 & 8 & 2.1 & 2.34 & 3.51 \\
$\mathrm{Ce}$ & 8 & 8 & 6.0 & 5.9 & 9.4 \\
$\mathrm{Nd}$ & 6 & 20 & 4.3 & 4.4 & 5.9 \\
$\mathrm{Sm}$ & 1.7 & 5 & 1.5 & 1.39 & 2.01 \\
$\mathrm{Eu}$ & 0.63 & 10 & 0.54 & 0.53 & 0.8 \\
$\mathrm{Gd}$ & 2.3 & 15 & 1.8 & & \\
$\mathrm{Dy}$ & 2 & 30 & 2.1 & 2.3 & 3.2 \\
$\mathrm{Yb}$ & 1.5 & 5 & 1.45 & 1.38 & 2 \\
$\mathrm{Hf}$ & 1.2 & 8 & 1.31 & 1.03 & 1.34 \\
$\mathrm{Th}$ & 0.33 & 8 & 0.25 & 0.24 & 0.41 \\
\hline
\end{tabular}

References: ${ }^{a}$ Kurat et al. (2001); ${ }^{\mathrm{b}}$ Warren and Davis (1995).

quenched to fine-grained rocks, and possibly formed some of the coarse-grained doleritic angrites. Melts in D'Orbigny, however, did not crystallize but were quenched to glass. While their chemical composition is that of a parental melt, their petrographic occurrence is that of a residual phase.

If glasses have not been injected into the rock, they must have formed in or close to the places where they are found now. Glass is filling part of the open druses or a few of the abundant spheres, and there are no signs of far-reaching mobility of the melts. Furthermore, because the glasses have the chemical composition of the bulk rock, they cannot be residual melts quenched to glass at the end of the crystallization of the rock.

Estimates of the crystallization sequences (Ariskin et al., 1997) calibrated relative to experimental data on crystallization of angrite melts (McKay et al., 1988) [simulation of experiments were carried out for $1 \mathrm{~atm}$. pressure and oxygen fugacity of $1 \log$ unit above the iron-wüstite buffer, in agreement with McKay et al. (1994)] indicate that after crystallization of anorthite, olivine, and augite, the glass composition is as follows: $\mathrm{SiO}_{2}$ (39.8 wt.\%), $\mathrm{TiO}_{2}$ (6.1 wt.\%), $\mathrm{Al}_{2} \mathrm{O}_{3}$ (5.4 wt.\%), $\mathrm{FeO}$ (27.5 wt.\%), $\mathrm{MnO}$ (0.33 wt.\%), $\mathrm{MgO}$ (2.93 wt.\%), and $\mathrm{CaO}$ (17.9 wt.\%). This composition has only $50 \%$ as much $\mathrm{MgO}$ and $\mathrm{Al}_{2} \mathrm{O}_{3}$ and around four times as much $\mathrm{TiO}_{2}$ as the D'Orbigny glasses (Table 1).

D'Orbigny glasses can be considered parental melts from which most phases of angrites could have crystallized. However, the rock could not have formed by crystallization of such a melt because this melt has anorthite at the liquidus, which is followed by olivine only after $\sim 10 \%$ of the liquid has crystallized. This cannot account for the intimate intergrowths of anorthite + olivine that form the large part of the rock.

Another argument against igneous formation of glasses is given by the glass inclusions. Primary glass inclusions trapped in olivines (one of the first phases to crystallize in the rock) can be divided, according to their chemical composition, into two groups: a first group (A) enriched in $\mathrm{Al}_{2} \mathrm{O}_{3}$ and depleted in $\mathrm{FeO}$ contents as compared with all other glasses (glass inclusions 6 , 3,5 , and 1); and a second group (B) that has contents of $\mathrm{FeO}$,

Table 3. LA-ICP-MS analyses (in ppm) of glass spheres, glass patches, and glass with bubbles from D’Orbigny.

\begin{tabular}{|c|c|c|c|c|c|c|c|c|c|c|}
\hline Element & GS & GS & GP & GP & GP & GP & GP & GWB & GWB & GWB \\
\hline $\mathrm{Li}$ & 4.43 & 5.68 & 4.64 & 3.14 & 5.01 & 4.68 & 5.11 & 8.46 & 4.66 & 8.11 \\
\hline $\mathrm{Ca}$ & 97130 & 76500 & 85000 & 96800 & 87400 & 86800 & 100800 & 105400 & 95500 & 83000 \\
\hline $\mathrm{Sc}$ & 39.0 & 29.3 & 33.1 & 53.9 & 36.6 & 28.8 & 37.4 & 50.9 & 24.6 & 41.8 \\
\hline $\mathrm{Ti}$ & 4300 & 3750 & 4670 & 5600 & 4500 & 3660 & 3980 & 4320 & 2200 & 3850 \\
\hline V & 110 & 92 & 105 & 157 & 113 & 94 & 117 & 117 & 64 & 92 \\
\hline $\mathrm{Cr}$ & 260 & 240 & 330 & 300 & 350 & 270 & 340 & 690 & 330 & 540 \\
\hline $\mathrm{Mn}$ & 1750 & 1400 & 1690 & 1390 & 1760 & 1470 & 1810 & 1830 & 1000 & 1500 \\
\hline $\mathrm{Sr}$ & 88.0 & 87.6 & 75.2 & 54.9 & 84.4 & 92.7 & 92.4 & 131.0 & 128.0 & 108.1 \\
\hline$Y$ & 13.6 & 13.9 & 11.1 & 11.1 & 12.0 & 10.4 & 12.7 & 27.2 & 9.9 & 19.3 \\
\hline $\mathrm{Zr}$ & 38.0 & 39.9 & 32.0 & 44.3 & 33.3 & 27.7 & 33.9 & 75.4 & 29.7 & 57.0 \\
\hline $\mathrm{Nb}$ & 3.01 & 3.43 & 2.67 & 1.81 & 2.86 & 2.60 & 2.99 & 3.60 & 1.89 & 3.46 \\
\hline $\mathrm{La}$ & 2.58 & 3.38 & 2.40 & 1.76 & 2.43 & 2.08 & 2.75 & 4.19 & 1.85 & 3.48 \\
\hline $\mathrm{Ce}$ & 6.71 & 8.56 & 6.45 & 5.22 & 6.73 & 5.80 & 7.58 & 8.70 & 4.22 & 7.70 \\
\hline $\mathrm{Nd}$ & 4.97 & 6.49 & 4.63 & 4.25 & 4.46 & 3.92 & 5.67 & 7.17 & 3.03 & 5.87 \\
\hline $\mathrm{Sm}$ & 1.48 & 1.93 & 1.34 & 1.45 & 1.48 & 1.09 & 1.63 & 2.91 & 1.74 & 2.10 \\
\hline $\mathrm{Eu}$ & 0.62 & 0.84 & 0.65 & 0.54 & 0.54 & 0.60 & 0.73 & 0.90 & 0.57 & 0.70 \\
\hline $\mathrm{Tb}$ & 0.34 & 0.48 & 0.32 & 0.31 & 0.29 & 0.26 & 0.34 & 0.54 & 0.22 & 0.36 \\
\hline Gd & 1.88 & 2.53 & 1.90 & 1.88 & 1.72 & 1.49 & 2.17 & 3.01 & 1.31 & 2.17 \\
\hline Dy & 2.35 & 3.18 & 2.31 & 2.14 & 2.12 & 1.81 & 2.65 & 3.57 & 1.68 & 2.34 \\
\hline Ho & 0.48 & 0.69 & 0.46 & 0.48 & 0.46 & 0.39 & 0.61 & 0.80 & 0.39 & 0.60 \\
\hline $\mathrm{Tm}$ & 0.22 & 0.29 & 0.21 & 0.19 & 0.21 & 0.16 & 0.25 & 0.40 & 0.17 & 0.26 \\
\hline $\mathrm{Yb}$ & 1.55 & 1.98 & 1.44 & 1.51 & 1.40 & 1.16 & 1.81 & 2.67 & 1.12 & 1.63 \\
\hline $\mathrm{Lu}$ & 0.21 & 0.30 & 0.20 & 0.22 & 0.20 & 0.17 & 0.24 & 0.37 & 0.19 & 0.27 \\
\hline Hf & 1.05 & 1.37 & 1.03 & 1.69 & 0.93 & 0.72 & 1.10 & 2.04 & 0.83 & 1.25 \\
\hline $\mathrm{Ta}$ & 0.14 & 0.21 & 0.14 & 0.10 & 0.15 & 0.14 & 0.17 & 0.26 & 0.11 & 0.17 \\
\hline $\mathrm{Th}$ & 0.29 & 0.40 & 0.31 & 0.22 & 0.29 & 0.25 & 0.34 & 0.67 & 0.34 & 0.62 \\
\hline $\mathrm{U}$ & 0.08 & 0.11 & 0.09 & 0.06 & 0.10 & 0.08 & 0.09 & 0.15 & 0.10 & 0.15 \\
\hline
\end{tabular}

$\mathrm{GS}=$ glass sphere; GP = glass patches; GWB = glass with bubbles. 
Table 4. Ion microprobe analyses (in ppm) of glasses of glass inclusions, glass pockets, olivines, and plagioclase in D'Orbigny.

\begin{tabular}{|c|c|c|c|c|c|c|c|c|c|c|c|c|c|c|c|c|c|c|c|c|c|c|c|c|}
\hline $\begin{array}{l}\text { Ele- } \\
\text { ment }\end{array}$ & $\begin{array}{c}\text { Glass } \\
1\end{array}$ & error & $\begin{array}{c}\text { Olivine } \\
1\end{array}$ & error & $\begin{array}{c}\text { Glass } \\
3\end{array}$ & error & $\begin{array}{c}\text { Olivine } \\
3\end{array}$ & error & $\begin{array}{c}\text { Glass } \\
5\end{array}$ & error & $\begin{array}{c}\text { Glass } \\
6\end{array}$ & error & $\begin{array}{c}\text { GP } \\
5 c-e\end{array}$ & error & $\begin{array}{c}\text { GP } \\
5 a-b\end{array}$ & error & $\begin{array}{c}\text { Olivine } \\
5\end{array}$ & error & $\begin{array}{c}\text { GP } \\
6 \mathrm{a}-\mathrm{c}\end{array}$ & error & $\begin{array}{c}\text { Olivine } \\
6\end{array}$ & error & Plag. & error \\
\hline $\mathrm{i}$ & 4.4 & 0.1 & 9.9 & 0.2 & 8.7 & 0.2 & 5.4 & 0.07 & 8.5 & 0.4 & 8.3 & 0.3 & 1.3 & 0.3 & 5.6 & 0.2 & 7.4 & 0.08 & 9.3 & 0.3 & 3.6 & 0.06 & 6.8 & 0.07 \\
\hline $\mathrm{Be}$ & 0.07 & $<0.01$ & 0.06 & $<0.01$ & 0.16 & 0.01 & & & 0.14 & 0.02 & 0.17 & 0.02 & 0.16 & 0.01 & 0.06 & 0.07 & 0.004 & $<0.001$ & 0.3 & 0.02 & $<0.001$ & $<0.001$ & 0.08 & 0.004 \\
\hline B & 0.6 & 0.07 & 0.65 & 0.07 & 2 & 0.14 & 0.07 & 0.01 & 0.94 & 0.16 & 0.98 & 0.12 & 0.74 & 0.1 & 0.53 & 0.09 & 0.08 & 0.01 & 1.2 & 0.13 & 0.05 & 0.009 & 0.04 & 0.007 \\
\hline $\mathrm{P}$ & 660 & 350 & & & 480 & 340 & & & 400 & 340 & 450 & 330 & 470 & 330 & & & & & 900 & 330 & & & & \\
\hline K & 6.6 & 0.3 & 6.4 & 0.2 & 140 & 1.6 & 0.9 & 0.05 & 0.23 & 1 & 27 & 1 & 73 & 1 & 46 & 1 & 0.7 & 0.04 & 210 & 2.5 & 0.5 & 0.04 & 4.3 & 0.1 \\
\hline $\mathrm{Ca}$ & 99000 & 350 & 20000 & 200 & 68500 & 370 & 6500 & 565 & 52000 & 520 & 57000 & 480 & 60500 & 450 & 120000 & 610 & 8650 & 60 & 137000 & 450 & 5620 & 50 & 89900 & 80 \\
\hline $\mathrm{Sc}$ & 58 & 0.6 & 20 & 0.4 & 36 & 0.6 & 18 & 0.2 & 30 & 0.9 & 32 & 0.8 & 37 & 0.7 & 100 & 1 & 15 & 0.15 & 60 & 0.9 & 15.5 & 0.15 & 1.5 & 0.1 \\
\hline $\mathrm{Ti}$ & 4630 & 10 & 1060 & 4.5 & 3110 & 10 & 129 & 1 & 2260 & 14 & 2580 & 13 & 3040 & 10 & 7400 & 19 & 160 & 10 & 8500 & 20 & 100 & 0.9 & 55 & 0.5 \\
\hline V & 123 & 10 & 27 & 0.5 & 68 & 10 & 35 & 0.3 & 63 & 1.5 & 64 & 1.3 & 66 & 10 & 190 & 2 & 23 & 2 & 130 & 1.7 & 28 & 0.2 & 5 & 0.09 \\
\hline $\mathrm{Cr}$ & 500 & 2.5 & 310 & 2 & 310 & 2.5 & 550 & 1 & 400 & 4.5 & 370 & 4 & 314 & 2.5 & 415 & 3.5 & 370 & 1 & 250 & 3 & 450 & 1.2 & 1.5 & 0.06 \\
\hline $\mathrm{Mn}$ & 2800 & 7 & 5000 & 10 & 3240 & 9 & 3960 & 4 & 3230 & 15 & 3400 & 14 & 4300 & 12 & 4200 & 13 & 4500 & 4.5 & 2400 & 10 & 3500 & 3.9 & 96 & 0.5 \\
\hline $\mathrm{Fe}$ & 190000 & 280 & 327000 & 600 & 224000 & 410 & 290000 & 200 & 2250 & 670 & 230000 & 600 & 300000 & 530 & 250000 & 530 & 310000 & 270 & 160000 & 400 & 250000 & 190 & 2700 & 17 \\
\hline Co & 120 & 2 & 172 & 2.5 & 135 & 2.8 & 200 & 1.4 & 145 & 4.5 & 142 & 4 & 153 & 3 & 96 & 2.9 & 190 & 1.3 & 78 & 2.8 & 185 & 1.3 & 6.6 & 0.2 \\
\hline $\mathrm{Rb}$ & 1.1 & 0.7 & & & & & 0.8 & 0.1 & 3.5 & 1.5 & & & 2.1 & 1.3 & & & 0.4 & 0.1 & & & 0.6 & 0.1 & & \\
\hline $\mathrm{Sr}$ & 17 & 0.4 & 11 & 0.3 & 67 & 1 & 0.06 & 0.006 & 48 & 1.4 & 53 & 1.3 & 52 & 1 & 14 & 0.6 & 0.9 & 0.03 & 66 & 1.3 & 0.05 & 0.006 & 134 & 0.6 \\
\hline Y & 17.5 & 0.4 & 5.3 & 0.2 & 12 & 0.4 & 0 & 0.02 & 10 & 0.6 & 9.5 & 0.5 & 16 & 0.5 & 17 & 0.6 & 0 & 0.04 & 34.5 & 0. & 0.4 & 0.02 & 0.09 & 0.006 \\
\hline $\mathrm{Zr}$ & 56 & 1 & 11 & 0.5 & 44 & 1 & 0.15 & 0.01 & 29 & 1.5 & 31.8 & 1.4 & 40 & 1 & 115 & 2.3 & 0.6 & 0.02 & 110 & 2.4 & 0.13 & 0.009 & 0.02 & 0.005 \\
\hline $\mathrm{Nb}$ & 1.7 & 0.14 & 1.1 & 0.1 & 2.5 & 0.2 & 002 & $<0.001$ & 1.8 & 0.18 & 1.8 & 0.2 & 2.8 & 0.2 & 0.53 & 0.06 & & 0.005 & 5.2 & 0.4 & 0.001 & $<0.001$ & & \\
\hline $\mathrm{Ba}$ & 1.5 & 0.09 & 5.2 & 0.3 & 34 & 1 & 0.05 & 0.009 & 13 & 1 & 16.5 & 1 & 87 & 2 & 3.2 & 0.3 & 0.54 & 0.04 & 6.5 & 0.6 & 0.06 & 0.01 & 7.6 & 0.2 \\
\hline $\mathrm{La}$ & 1.6 & 0.09 & 0.8 & 0.09 & 2.1 & 0.16 & 0.001 & $<0.001$ & 1.7 & 0.18 & 2 & 0.2 & 3.4 & 0.2 & 1 & 0.1 & 0.06 & 0.004 & 5 & 0.3 & 0.001 & $<0.001$ & 0.1 & 0.009 \\
\hline $\mathrm{Ce}$ & 4.4 & 0.2 & 2.1 & 0.16 & 4.8 & 0.4 & 0.005 & 0.001 & 3.8 & 0.4 & 4.8 & 0.4 & 7.8 & 0.4 & 3.9 & 0.28 & & 0.009 & 12.5 & 0.7 & 0.004 & 0.001 & & 0.01 \\
\hline $\operatorname{Pr}$ & 0 & 0.06 & 0.3 & 0.003 & 0.8 & 0.06 & 0.002 & $<0.001$ & 0.7 & 0.09 & 0.9 & 0.1 & 1.3 & 0.1 & 0.6 & 0.08 & $0 .($ & 0.002 & 2 & 0.15 & & & 0.026 & 0.003 \\
\hline $\mathrm{Nd}$ & 4.9 & 0.2 & 1.4 & 0.09 & 4.2 & 0.2 & 0.006 & 0.002 & 2.6 & 0.2 & 3.8 & 0.25 & 5 & 0.2 & 3.8 & 0.2 & 0.09 & 0.006 & 10 & 0.4 & 0.003 & 0.001 & 0.09 & 0.005 \\
\hline Sm & 1.4 & 0.1 & 0.4 & 0.06 & 1.2 & 0.1 & & & 1.2 & 0.1 & 1.1 & 0.1 & 1.6 & 0.1 & 1.7 & 0.2 & 0.04 & 0.005 & 3.4 & 0.3 & & & 0.02 & 0.004 \\
\hline $\mathrm{Eu}$ & 0.44 & 0.03 & 0.14 & 0.02 & 0.48 & 0.04 & & & 0.4 & 0.05 & 0.38 & 0.05 & 0.38 & 0.07 & 0.35 & 0.04 & 0.008 & 0.001 & 0.97 & 0.08 & 0.001 & $<0.001$ & 0.2 & 0.01 \\
\hline $\mathrm{Gd}$ & 2 & 0.25 & 0.2 & & 0. & 0.2 & 0.01 & 0.002 & 1.25 & 0.2 & 1.67 & 0.3 & 1.7 & 0.3 & 2 & 0.3 & & 0.006 & 4.2 & 0.5 & 0.009 & 0.002 & 0.02 & 0.004 \\
\hline $\mathrm{Tb}$ & 0.39 & 0.05 & 0.08 & 0.02 & 0.23 & 0.03 & 0.002 & $<0.001$ & 0.22 & 0.05 & 0.28 & 0.05 & 0.37 & 0.05 & 0.4 & 0.06 & 0.01 & 0.002 & 0.8 & 0.08 & 0.026 & $<0.001$ & 0.005 & 0.001 \\
\hline Dy & 3 & 0.15 & 0.6 & 0.05 & 2.2 & 0.13 & 0.04 & 0.004 & 1.7 & 0.14 & 2.2 & 0.18 & 2.76 & 0.16 & 2.9 & 0.2 & 0.1 & 0.06 & 5.6 & 0.3 & 0.03 & 0.003 & 0.014 & 0.002 \\
\hline Ho & .57 & 0.04 & 0 & .02 & 0.46 & 0.04 & 0.01 & 0.002 & 0.27 & 0.0 & 0.45 & 0. & 0.5 & 0.05 & 0.6 & 0.07 & & 0.002 & 1 & 0. & 0.012 & 0.002 & 0.004 & $<0.001$ \\
\hline $\mathrm{Er}$ & 1 & 0.1 & 0.4 & 0.05 & 1.37 & 0.09 & & & 1 & 0.1 & 1.2 & 0.1 & 1.5 & 0.1 & 1.9 & 1.5 & & 0.06 & 3.7 & 0. & 0.06 & 0.004 & 0.008 & 0.002 \\
\hline Tm & 0.28 & 0.03 & 0.08 & 0.02 & 0.19 & 0.03 & 0.01 & 0.002 & 0.17 & 0.03 & 0.2 & 0.04 & 0.3 & 0.03 & 0.3 & 0.04 & 0.03 & 0.002 & 0.5 & 0.06 & 0.02 & 0.002 & & \\
\hline $\mathrm{Yb}$ & 1.78 & 0.13 & 0.6 & 0.06 & 1.3 & 0.12 & & 0.01 & 0.95 & 0.15 & 1.2 & 0.14 & 1.4 & 0.13 & 1.8 & 0.2 & 0.23 & 0.01 & 3.2 & 0.27 & 0.1 & 0.01 & 0.014 & 0.003 \\
\hline $\mathrm{Lu}$ & 0.29 & 0.04 & 0.15 & 0.02 & 0.24 & 0.04 & 0.03 & 0.003 & 0.2 & 0.06 & 0.28 & 0.07 & 0.22 & 0.03 & 0.35 & 0.07 & 0.05 & 0.004 & 0.6 & 0.08 & 0.024 & 0.003 & & \\
\hline
\end{tabular}

Glass $1=$ Glass inclusion 1 ; GP 5a-b $=$ Glass pocket 5a-b; Plag $=$ Plagioclase. 
$\mathrm{Al}_{2} \mathrm{O}_{3}$, and $\mathrm{MgO}$ within the chemical compositional range of all other glasses (glass inclusions $\mathrm{A}, \mathrm{B}, \mathrm{C}$, and D). Besides the strong variation observed in the $\mathrm{FeO}$ contents of the glasses of both groups $(\sim 10 \mathrm{wt} . \%)$, the chemical composition of the host olivines of both groups varies within similar values, between 31 to 41 wt.\% $\mathrm{FeO}$ (group A) and 33 to 38.2 wt.\% FeO (group B). One possible way to explain this chemical variation is that glass inclusions of group A were reduced in their original size due to crystallization of a layer of the host mineral onto the inclusion walls during natural cooling.

Reverse-crystallization calculations made for glass inclusion 3 (the glass inclusion with the lowest $\mathrm{FeO}$ content) show that the inclusion wall must represent at least $40 \%$ of the inclusion volume for the $\mathrm{FeO}$ contents present in other glasses to be reached. The chemical composition of the glass of inclusion 3 after adding $40 \%$ of the host is as follows: $\mathrm{SiO}_{2}: 40.3$ wt. $\%$; $\mathrm{TiO}_{2}$ : 0.89 wt.\%; $\mathrm{Al}_{2} \mathrm{O}_{3}$ : 13 wt.\%; $\mathrm{FeO}: 18.6$ wt.\%; $\mathrm{MnO}: 0.2$ wt.\%; $\mathrm{CaO}: 14$ wt.\%; and $\mathrm{MgO}: 13.8$ wt.\%. This composition does match the $\mathrm{TiO}_{2}$ and $\mathrm{Al}_{2} \mathrm{O}_{3}$ contents of other glasses but is extremely rich in $\mathrm{MgO}$ as compared to the second group of inclusions as well as to all other glasses. The distribution coefficient $\mathrm{Kd}$ : $\mathrm{Fe} / \mathrm{Mg}$ [Kd: $(\mathrm{Fe} / \mathrm{Mg})_{\text {ol }} /(\mathrm{Fe} / \mathrm{Mg})_{\text {liq }}$ ] for the calculated glass 3 with the addition of $40 \%$ of the host is also extremely high (Kd: 0.8$)$ as compared to the equilibrium value of 0.317 (Roeder and Emslie, 1970). Moreover, if such an extensive crystallization of a layer of host mineral onto the walls of the glass inclusion took place, we must expect an enlargement of the shrinkage bubble due to the enlarged volume. However, we have not detected any difference in the bubble size between inclusions of groups A and B. This chemical variation in glasses of group $\mathrm{B}$ could be due to the metasomatic addition of $\mathrm{FeO}$ (as well as $\mathrm{Mn}$ and $\mathrm{Cr}$ - in exchange for $\mathrm{Mg}$ ) in an oxidation event during formation of the D'Orbigny rock.

\subsection{Formation of Glasses by Shock}

The origin of D'Orbigny glasses must have involved a process that can explain how a late liquid phase can have the composition of the bulk rock. A possible scenario could be the formation of glasses by melting of D'Orbigny bulk rock. This could be caused by an impact-melting event because impact melts usually preserve the bulk composition of the target rock. However, formation of D'Orbigny glasses by shock has to be excluded because no shock features are present while very delicate structures such as the hollow shells and crystal-lined druses are. In addition, glasses in D'Orbigny are as ancient as the rock itself (Jotter et al., 2002), making a shock origin highly improbable but indicating that the glass is of primary origin, having been formed contemporaneously with the rock.

\subsection{Chemical Interrelationships}

\subsubsection{Major and minor element contents of glasses seem to exclude an origin by partial melting}

The chemical composition of the glasses filling pore space and hollow shells resembles that of angrite bulk rocks, in particular that of D'Orbigny, Asuka 881371, and Sahara 99555. However, D'Orbigny glasses have low MgO contents as compared to Angra dos Reis, LEW 87051, and Asuka 99555; show the lowest $\mathrm{CaO} / \mathrm{Al}_{2} \mathrm{O}_{3}$ ratio (except for LEW 87051); and are at the higher end of the range in their $\mathrm{FeO}$ content (together with Asuka 881371 and Sahara 99555). Glasses have superchondritic $\mathrm{CaO} / \mathrm{Al}_{2} \mathrm{O}_{3}$ ratios, similar to the angrites (Fig. 6). The compositional range is small for glass patches and spheres but large for inclusion glasses in olivine and glass pockets, which range from 5.8 wt. $\%$ to 22 wt. $\%$ in $\mathrm{Al}_{2} \mathrm{O}_{3}$ contents. The $\mathrm{CaO}$ and $\mathrm{TiO}_{2}$ contents are within the range of the angrites bulk rock compositions. The $\mathrm{CaO} / \mathrm{TiO}_{2}$ ratio of the glass patches and the glass sphere are close to chondritic and similar to those of D'Orbigny, Asuka 881371, and Sahara 99555. CaO and $\mathrm{TiO}_{2}$ contents of inclusion glasses in olivine are high but are within the range defined by the compositions of LEW 86010 and Angra dos Reis (Fig. 8). The highest $\mathrm{TiO}_{2}$ content is observed in glass pockets where it varies from 1.5 to $4.1 \mathrm{wt}$. \% . The $\mathrm{FeO}$ and $\mathrm{Al}_{2} \mathrm{O}_{3}$ contents of glass patches, glass spheres, and foamy glass (GWB) are within the range of angrites bulk rock composition. However, inclusion glasses and glass pockets show an anticorrelation between $\mathrm{FeO}$ and $\mathrm{Al}_{2} \mathrm{O}_{3}$, pointing towards a replacement of $\mathrm{Al}_{2} \mathrm{O}_{3}$ by $\mathrm{FeO}$ (Fig. 7). The correlation line through glass inclusions and some glass pockets $(\Delta \mathrm{FeO} /$ $\left.\Delta \mathrm{Al}_{2} \mathrm{O}_{3} \sim-1.4\right)$ seems to support an $\mathrm{Fe}-\mathrm{Al}$ exchange reaction (mole $\mathrm{FeO} / 1 / 2 \mathrm{~mol} \mathrm{Al}_{2} \mathrm{O}_{3}$ : 1.4). The $\mathrm{FeO}$ and $\mathrm{MnO}$ contents of glasses are close to the $\mathrm{CI}$ chondritic values, with the exception of foamy glass (GWB), which shows slightly higher $\mathrm{MnO}$ contents than all others and the glasses of glass inclusions (Fig. 12), which cover the whole range of $\mathrm{FeO}$ and $\mathrm{MnO}$ contents, from values similar to those in Angra dos Reis to CI chondritic ones.

Inclusion glasses of group A have low contents of $\mathrm{FeO}$, with the exception of glass inclusion 1, which is crosscut by a fracture (arrow in Fig. 13A). This glass is richer in $\mathrm{FeO}$ and $\mathrm{MgO}$ and it is poorer in $\mathrm{Al}_{2} \mathrm{O}_{3}$ than the others. Apparently, an elemental exchange has taken place whereby $\mathrm{Fe}, \mathrm{Mn}$, and $\mathrm{Mg}$ were exchanged for Al. All other elements seem not to have been affected. As a result, glass 1 became highly olivinenormative compared to all other group A glass inclusions in olivine (20 vs. 6 wt.\%, Table 1). All other glasses show an anticorrelation between the $\mathrm{FeO}$ and $\mathrm{MgO}$ contents (e.g., glass inclusions of group B, Fig. 13A), suggesting a replacement of $\mathrm{MgO}$ by $\mathrm{FeO}$, similar to what is observed in glasses from carbonaceous chondrites. Moreover, this diagram shows three correlation lines, the first for glass inclusions $\mathrm{B}$, the second for GP 5c-e + GP 6d-g, and the third for GP 6a-c + GP 5a-b. The three lines have $\Delta \mathrm{MgO} / \Delta \mathrm{FeO}$ ratios of $0.56,0.76$, and 0.57 , respectively, suggesting that these subparallel anticorrelations can be the result of $\mathrm{Mg}-\mathrm{Fe}$ exchange (moleMgO/moleFeO: $0.56)$ with increasing $\mathrm{Fe}^{2+}$ activity. Glasses of glass pockets show large variations in $\mathrm{TiO}_{2}$ and $\mathrm{Al}_{2} \mathrm{O}_{3}$ contents (Fig. 13B). Surprisingly, the glasses of glass pockets 6 and 5 vary in their $\mathrm{Al}_{2} \mathrm{O}_{3}$ and $\mathrm{TiO}_{2}$ contents (Table 1, Fig. 13B). Because these two elements do not enter the structure of the host olivine, the possibility that this inhomogeneous distribution is due to reactions with the host can be ruled out. Because glasses from glass pockets 6a-c and 6d-g are hosted by the same olivine (that is, both have formed contemporaneously) and because the only petrographic difference between both is that glass pocket $6 \mathrm{a}-\mathrm{c}$ is crosscut by a fracture (Fig. 5B), it is possible that $\mathrm{Ti}$ and $\mathrm{Al}$ have been mobilized during one of the oxidation processes that affected the rock (cf. Kurat et al., 2002). These authors sug- 


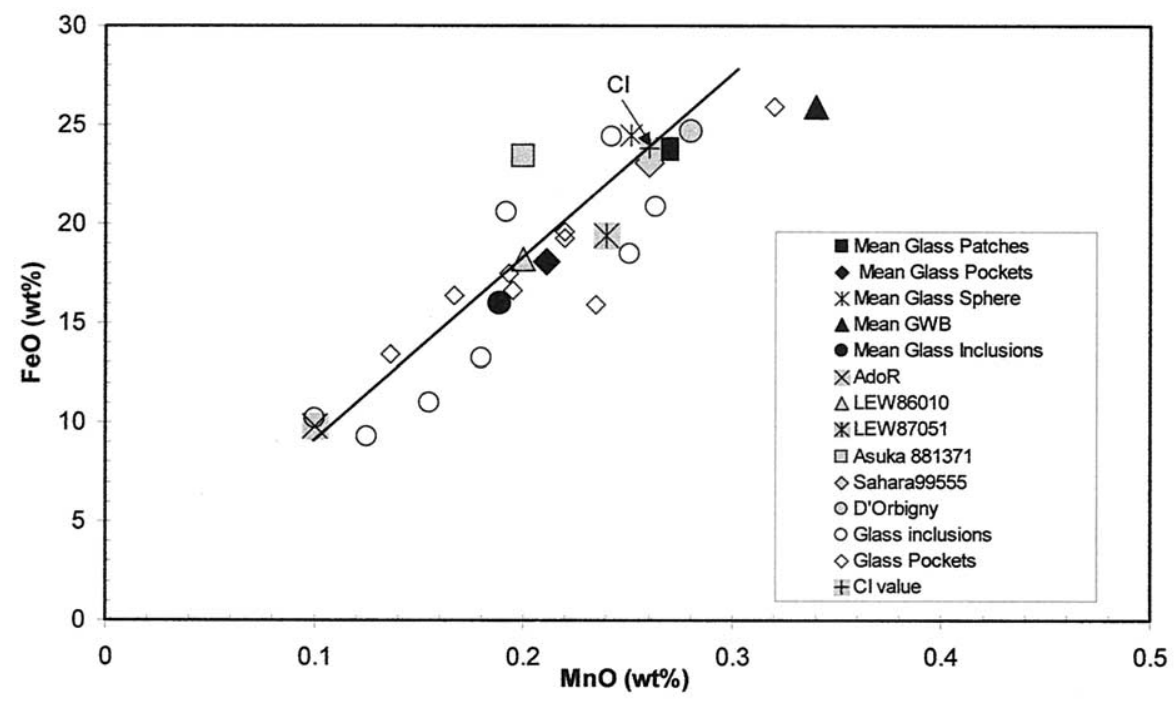

Fig. 12. FeO vs. MnO diagram of all types of glasses in D'Orbigny. Single data of glass inclusions in olivine show a trend from values similar to Angra dos Reis (AdoR) to chondritic (arrow) (CI, Anders and Grevesse, 1989) values. The FeO/MnO ratios in most glasses (and bulk angrites) are similar to that of CI chondrites.

gested that $\mathrm{Ca}, \mathrm{Al}, \mathrm{Ti}$, and $\mathrm{Si}$ must have been mobilized from preexisting phases (possibly those constituting the solid spheres) allowing growth of augite, Ca-olivine, kirschsteinite, and ulvöspinel pneumatolytically. Accordingly, the mobilization of $\mathrm{Ca}, \mathrm{Al}$, and $\mathrm{Ti}$ (all highly refractory elements under solar nebula, i.e., reducing, conditions) indicates an oxidizing event, as these elements form volatile species under oxidizing conditions (e.g., Hashimoto, 1992).

Another particular feature of D'Orbigny is the presence of volatile elements such as $\mathrm{C}$ and $\mathrm{N}$ in inclusion glasses. The way $\mathrm{C}$ and $\mathrm{N}$ have been stored in the glasses is different from that observed in inclusion glasses in olivines of carbonaceous chondrites (Varela et al., 2000, 2003). In chondrites, both elements are present in variable amounts in the same glass inclusion. In D'Orbigny this is not the case, as the two glass inclusions that contain nitrogen are free of carbon and vice versa. This particular distribution needs to be studied in more detail. However, the fact that extremely volatile elements are present in an otherwise volatile-free rock suggests that they likely were incorporated into the glass by a process similar to one that has been proposed for inclusion glasses in olivines of carbonaceous chondrites, i.e., by the incorporation of a solid refractory phase that was subsequently oxidized and transformed into volatile species.

In summary, 1) the abundance of refractory elements (e.g., $\mathrm{Al}, \mathrm{Ti}, \mathrm{Ca}$ ) in glasses at $\sim 10 \times \mathrm{CI}$ abundances and that of $\mathrm{FeO}$ and $\mathrm{MnO}$ similar to those in CI chondrites, 2) the $\mathrm{CaO} / \mathrm{TiO}_{2}$ and $\mathrm{FeO} / \mathrm{MnO}$ ratios being close to those in $\mathrm{CI}$ chondrites, and 3 ) the presence of $\mathrm{C}$ and $\mathrm{N}$ in inclusion glasses, similar to that observed in glass inclusions in olivines of carbonaceous chondrites, indicate a link between D'Orbigny glasses and inclusion glasses in olivines of carbonaceous chondrites.

\subsubsection{Trace element contents of glasses suggest a condensation origin from a chondritic reservoir}

Major, minor, and trace element contents of glass patches, glass spheres, and glass with abundant bubbles fall within narrow ranges of variation (Table 2, Figs. 6, 8, and 9) and are very similar to those of D'Orbigny bulk rock (Tables 2, 3, and 4, Figs. 6 and 8), except for Ni and $\mathrm{Sr}$ (72 vs. 28 and 70 vs. 120, respectively, Table 2). An important feature of all glasses is that their trace element contents are independent of the major element contents. That is, fertile melts (e.g., glass spheres, glass patches) and residual melts (e.g., glass inclusions and glass pockets) have the same contents, which is not possible in an igneous system where the first, fertile melt shall have the trace element abundances of the rock and the residual melt much higher contents $(5-10 \times$ rock).

These glasses are strongly depleted in volatile lithophile elements, a feature similar to that observed in inclusion glasses in olivines of carbonaceous chondrites (e.g., Varela et al., 2002 a). Because all refractory lithophile elements have unfractionated relative abundances in all these objects (with the exception of $\mathrm{Al}$ and $\mathrm{Sc}$ as discussed further), a condensation origin from a chondritic reservoir seems to be likely.

An origin by partial melting of a chondritic source is excluded because no elemental fractionation related to compatibility can be detected. The abundance pattern of the refractory elements strongly suggests an origin from a source whose refractory elements had chondritic relative abundances (Fig. 14).

Compared to glass inclusions in olivines of carbonaceous chondrites, the major glasses of D'Orbigny as well as D'Orbigny bulk rock have a distinct deficit in Sc compared to all other refractory elements. They share this feature with all angrites (e.g., Warren and Davis, 1995) and eucrites (e.g., Mittlefehldt et al., 1998). Therefore the source of these objects or their precursors must have been depleted in this element or the depletion is of secondary origin. A primary fractionation should also affect other elements, such as highly refractory elements in case of a cosmochemical fractionation or geochemically related elements in case of a crystal-liquid fractionation. Neither of these fractionations is apparent from elemental 


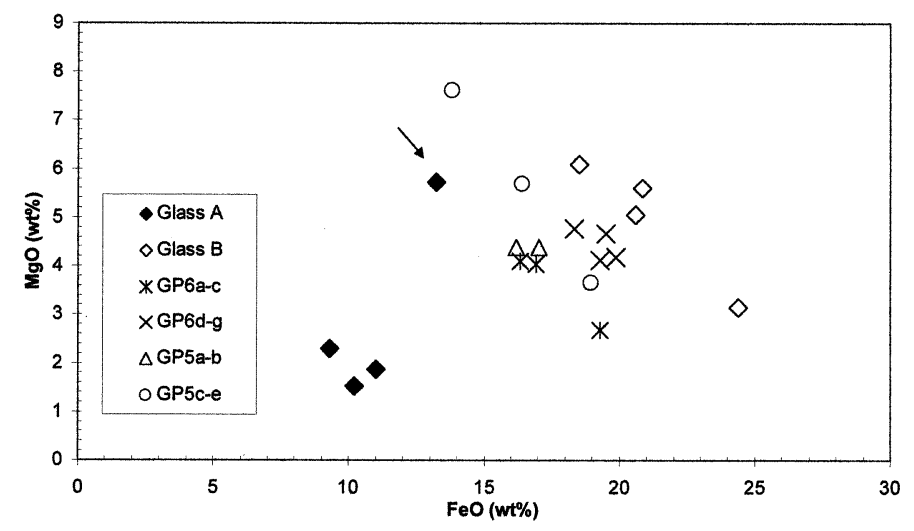

B

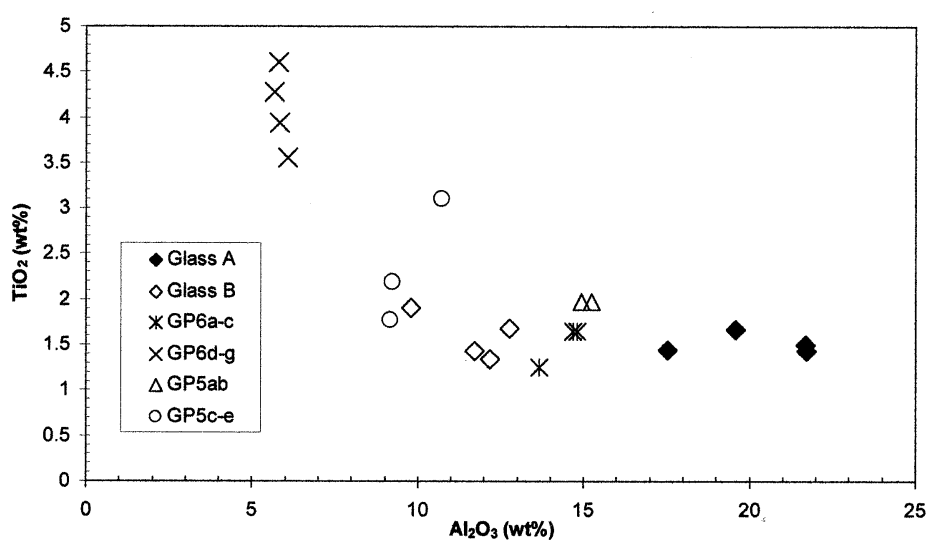

Fig. 13. Compositional variation diagram of inclusion glasses in olivine and glass pockets in D'Orbigny. (A) FeO vs. $\mathrm{MgO}$ : Chemical compositions of glasses show a wide spread. This compositional variation cannot be of primary origin. Glass inclusions of group $\mathrm{A}$ have low $\mathrm{FeO}$ and $\mathrm{MgO}$ contents which possibly indicate that its original composition had even less $\mathrm{FeO}$ and that the glass composition as observed now is the result of exchange reactions between the original glass and an external source (arrow points to Glass 1, see text). This diagram shows subparallel anticorrelations through the data,

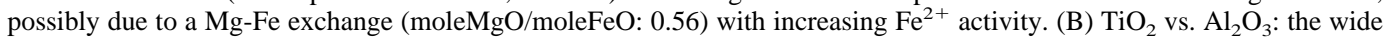
spread in $\mathrm{Al}_{2} \mathrm{O}_{3}$ content appears to be of secondary origin. The primitive glass has an $\mathrm{Al}_{2} \mathrm{O}_{3}$ content and variable content of $\mathrm{TiO}_{2}$ comparable to that of inclusion glasses in olivines of carbonaceous chondrites (Varela et al., 2002a).

abundances in our glasses and in bulk angrites, with the exception of $\mathrm{Al}$, which is also depleted with respect to other refractory elements. A possible mechanism could be loss of Sc and Al via metasomatic elemental exchange between the glasses and the rocks on one hand and a fluid phase at the other side. Such a process also is needed to explain the abundance of moderately volatile elements such as $\mathrm{V}, \mathrm{Cr}, \mathrm{Mn}, \mathrm{Fe}$, and $\mathrm{Li}$. The total lack of volatile elements such as $\mathrm{Na}$ or $\mathrm{K}$ in conjunction with the abundance of refractory elements could be interpreted as being due to vapor fractionation in a condensation process. These elements were not available during the metasomatic exchange of $\mathrm{Mg}, \mathrm{Al}$, and $\mathrm{Sc}$-from the solid-for $\mathrm{V}, \mathrm{Mn}$, $\mathrm{Fe}$, and $\mathrm{Li}$ from the fluid. In this way, the solid systems could have become depleted in the mobilized refractory elements and enriched in the moderately volatile elements.

Refractory trace element abundances of most inclusion glasses as well as those of the glass pockets (both glasses formed contemporaneously with the olivine) are around $10 \times$ CI abundances (Figs. 10, 11), similar to those of glass patches, glass spheres, and the foamy glass, and are unfractionated (Fig. 9 ). These types of glasses are thus chemically very similar to the common glasses, indicating a common origin. However, at least one glass inclusion in olivine (glass 1) (Fig. 10) and most glass pockets (Fig. 11) show slight deviations from the unfractionated trace element abundance pattern. Glass inclusion 1 is depleted in $\mathrm{Sr}, \mathrm{Ba}, \mathrm{Be}$, and $\mathrm{Nb}$ with respect to the refractory elements. This indicates anorthite fractionation, which is also supported by the low $\mathrm{La}_{\mathrm{N}} / \mathrm{Lu}_{\mathrm{N}}$ ratio and the small negative $\mathrm{Eu}$ anomaly. The $\mathrm{Nb}$ anomaly must be due to co-precipitation of another phase. A very similar fractionation is present in glass pockets, especially GP 5a-b (Fig. 11). Moreover, major and trace element abundances of glass pockets $5 \mathrm{c}-\mathrm{e}$ and $5 \mathrm{a}-\mathrm{b}$, which are hosted by a single olivine, are different from each other. The latter has higher contents of $\mathrm{Ti}$ and $\mathrm{Sc}$ and lower contents 


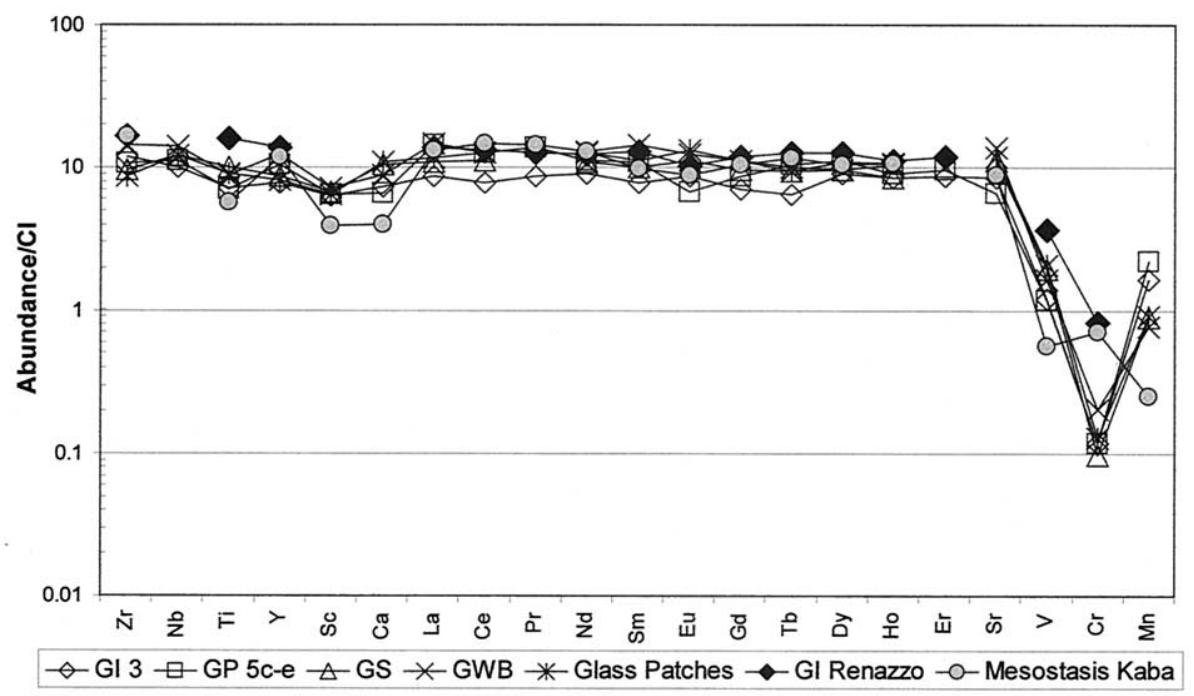

Fig. 14. CI-normalized trace element abundances in glass inclusions (GI), glass pockets (GP), glass spheres (GS), glass with bubbles (GWB), and glass patches (Glass Patches) from D'Orbigny and glasses from: glass inclusions in olivine in the Renazzo CR chondrite (GI Renazzo) and the mesostasis glass from a chondrule in the Kaba CV3 chondrite (Mesostasis Kaba). The very similar refractory trace element abundances in glasses of angrites and carbonaceous chondrites indicate derivation from a common source.

of $\mathrm{Nb}, \mathrm{Sr}$, and $\mathrm{Ba}$ than the former, and fractionated REE (Fig. 11). Calcium, $\mathrm{Eu}, \mathrm{Sr}, \mathrm{Ba}$, and $\mathrm{Li}$ contents in glass pockets suggest plagioclase precipitation from the melt (Fig. 11), indicating that formation of some of these glass pockets was contemporaneous with plagioclase formation. Plagioclase crystal fractionation of the chemical composition of these glass pockets indicates isolation of these melts from the vapor, preventing replenishment of the elements needed for plagioclase precipitation-as is documented by the common glasses.
Surprisingly, the contents of $\mathrm{V}, \mathrm{Cr}, \mathrm{Mn}, \mathrm{Fe}$, and $\mathrm{Li}$ in the olivine and glass inclusions are approximately in equilibrium (Figs. 10 and 15). While the primary trace elements are out of equilibrium, the secondary elements $\mathrm{Cr}, \mathrm{Mn}$, and $\mathrm{Fe}$ are not. This situation is similar to what has been already observed in glass inclusions and their hosts in CR chondrites and in Allende dark inclusions (Varela et al., 2002a,b). Obviously, the metasomatic introduction of these elements into both, the olivines and their glass inclusions, took place under conditions that

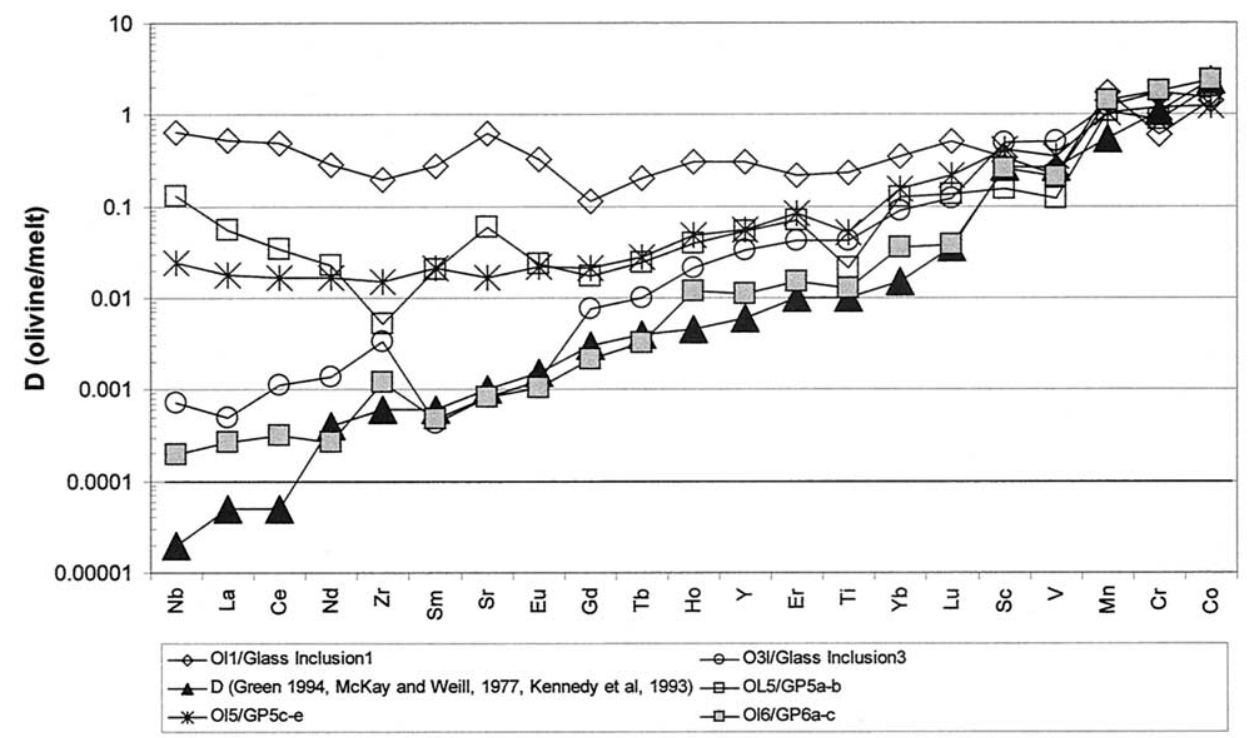

Fig. 15. Apparent trace element distribution between two types of glasses and their olivine host: two glass inclusions (glass inclusion 3 [Ol/Glass3] and glass inclusion 1 [Ol/Glass1]) and two glass pockets (GP 5 a-b and GP 5c-e), both hosted by a single olivine (O15) and the (GP 6a-c). Olivine-liquid distribution coefficients (D) from Green (1994), McKay and Weill (1997), and Kennedy et al. (1993) are given for comparison. 
allowed proper diffusion of these elements in these phases. Because most of these elements (e.g., Fe, Mn, Li) have higher diffusion rates than most tri- and tetravalent trace elements, their equilibrium partitioning could have been achieved while disequilibrium prevailed in the distribution of other elements. The depletion of all glasses in siderophile elements and in $\mathrm{V}$ with respect to the refractory lithophile elements could be the result of reducing conditions during their formation. Vanadium, like $\mathrm{Fe}, \mathrm{Mn}, \mathrm{Cr}$, and $\mathrm{Li}$, could have been added to the glass (and rock) in a late metasomatic event (Kurat et al., 2002). Because the $\mathrm{Fe} / \mathrm{Mn}$ ratio of the glass (and rock) is also close to chondritic (Fig. 12), the source of that metasomatic agent likely also had chondritic elemental abundances.

Elemental partitioning between glass and olivine. The olivine-liquid distribution coefficient (D) is discussed on the basis of the two types of glasses that are hosted in olivine, i.e., the glass inclusions and the glass pockets (Fig. 15). In the case of the glass inclusions we are considering two cases: $\mathrm{D}_{\text {olivine-glass }}$ inclusion3 (because olivine 3 shows highly fractionated trace element abundances, Fig. 10) and $\mathrm{D}_{\text {olivine-glass inclusion1 (be- }}$ cause olivine 1 has practically unfractionated trace element abundances, Fig. 10). We will discuss two glass pockets (GP 5 $\mathrm{a}-\mathrm{b}$ and GP 5c-e) that are hosted by a single olivine (O15) and the glass pocket GP $6 \mathrm{a}-\mathrm{c}$. Trace element distributions between olivine and GP 6a-c have a relatively close correspondence between the experimental distribution coefficient (Green, 1994; McKay and Weill, 1977; Kennedy et al., 1993) and the observed D values with the exception of $\mathrm{La}, \mathrm{Ce}$, and $\mathrm{Zr}$. Olivine and glass inclusion 3 are not equilibrated as trace element abundances in the olivine mimic constantly distribution coefficients that are clearly higher (with the exception of Sm, Sr, and $\mathrm{Eu}$ ) than the experimental values (Fig. 15). The olivineliquid distribution coefficients of GP 5c-e and GP 5a-b slightly differ from one another (GP 5a-b has higher D values of $\mathrm{Nb}$, $\mathrm{La}, \mathrm{Ce}$, and $\mathrm{Sr}$ and lower $\mathrm{D}$ values of $\mathrm{Zr}$ as compared to GP $5 \mathrm{c}-\mathrm{e})$, although they coexist in the same host olivine. The trace elements of both of them are not fractionated according to olivine/liquid partitioning. Olivine and glass inclusion 1 trace element abundances do not follow the olivine-liquid distribution coefficient at all (Fig. 15). The flat trace element abundance pattern signal of $\mathrm{D}_{\text {olivine-glass inclusion 1 }}$ denotes conditions totally out of equilibrium and a total absence of thermal processing of the rock.

\subsection{A Primary Origin of Glasses}

\subsubsection{A possible genetic model for D'Orbigny glasses}

Up to this point of the discussion we have confronted the reader with different arguments that indicate that these glasses could have been the result of a condensation process. However, angrites are widely believed to be igneous rocks. Thus, before discussing the genetic model of D'Orbigny glasses we will first introduce to the reader the possible nonigneous model of the D'Orbigny angrite. This will provide a better understanding of the different processes (e.g., oxidizing, reducing) that seem to have affected both, the rock and the coexisting glasses.

Based on the study of the main mass of D'Orbigny, its shape, structure, and textures, as well as of its mineral and bulk chemical composition, Kurat et al. (2002) proposed an unusual and novel scenario for its genesis. According to this model, the rock possibly grew by precipitation of a variety of phases from a vapor under changing redox conditions ranging from strongly reducing during the early to highly oxidizing during the final stages. Thereby the mineralogy was changing by adaptation to the changing conditions, possibly covering a wide range from sulfides to the silicates that are now present. Consequently, the history of D'Orbigny appears to be governed by phase stabilities and instabilities within a reactive vapor/fluid phase. Because the abundances of refractory lithophile elements in the rock are in chondritic proportion, the source, i.e., the vapor, likely had a chondritic chemical composition. Also the vapor in contact with the rock at the end of its growth history had chondritic relative abundances in its moderately volatile elements as is recorded by the chondritic $\mathrm{FeO} / \mathrm{MnO}$ ratio of the rock. According to Kurat et al. (2002), D'Orbigny is an example of the formation of an achondritic rock from a chondritic source. This source could have been the solar nebula, albeit not under canonical conditions prevailing. However, D'Orbigny provides us with a record of changing conditions ranging from extremely reducing (formation of enstatite meteorite) to highly oxidizing (formation of $\mathrm{Mg}$-free $\mathrm{Fe}$ silicates). The sequence of events involved in D'Orbigny formation could have been as follows: 1) Spheres from an unknown but nonsilicate phase $(\mathrm{CaS}$ ?) formed and vanished during the later history of the rock. 2) On top of these spheres olivine-anorthite intergrowths precipitated forming silicate shells. 3) Intergrowths of anorthite and olivine also formed a fluffy network with abundant large open spaces. 4) Conditions changed and became more oxidizing, causing mobilization of $\mathrm{Ca}$ by breakdown of preexisting phases (e.g., CaS spheres). That caused 5) emptying of the olivine-anorthite shells and 6) crystallization of augite and, finally, 7) crystallization of ferroan augites and precipitation of Ca-olivine, kirschsteinite, and ulvöspinel.

The model of formation of glasses explained below, based on the proposed nonigneous formation model of this rock, appears to account for many, if not all, of the chemical and petrographic features of glasses.

\subsubsection{Model of glass formation}

Here we will discuss a possible model for the formation of glasses, dealing with glass inclusions and glass pockets on the one hand, and glasses filling open spaces, on the other. The main difference between them seems to be the way they had behaved: as closed systems (e.g., glass inclusions and glass pockets) or open systems (e.g., glasses filling open spaces). Despite the chemical similarities between these glasses, their formation cannot have been simultaneous, because the glass inclusions and glass pockets were trapped during the growing of the first phases in the rock (olivine and plagioclase) while those glasses filling open spaces needed to have voids available in the rock, that is, they have been incorporated after the formation of the void space. The absence of physical evidence for movements of melts (i.e., infiltration or melt flows) indicates that glasses could only have formed contemporaneously with the rock, as is also documented by lead isotope dating (Jotter et al., 2002). However, all types of glasses appear to have had a similar source and to have experienced similar redox conditions and metasomatic exchange reactions. 
Glasses share many, if not all, of their features with inclusion glasses in olivines of carbonaceous chondrites (Fig. 14). Similarly, trace element abundances in D’Orbigny glasses appear to be the result of a volatility-related process. Thus, it is likely that the origin of D'Orbigny glasses has been governed by a process similar to that responsible for the formation of glass inclusions in olivine of carbonaceous chondrites. That is, glasses could have been formed by vapor-liquid-solid growth or liquid phase epitaxy (Givargizov, 1987; Kurat et al., 1997; Varela et al., 2002a) during olivine formation. The precursor liquid of the glass must have been present in small amounts like a thin film wetting the crystal-vapor interface and interstitial spaces and facilitated growth of large crystals from the vapor. Glass inclusions, as well as glass pockets, could represent a sample of this melt, trapped and subsequently quenched during olivine formation. These glasses, shielded by their host crystals, should have behaved as closed systems. Thus, they were partially protected from the metasomatic events and kept a composition closer to the original one, unlike all other glasses. The variation in their chemical composition then allows tracking of the chemical changes prevailing during D'Orbigny formation. This variation mainly reflects crystal fractionation and metasomatic exchange reactions with an external source. For example, the chemical composition of glass inclusion 3, poor in $\mathrm{FeO}$ and $\mathrm{MgO}$ suggests that olivine had already crystallized from that fluid/melt. The existence of devitrified glass inclusions in olivine (e.g., Fig. 4C) is suggestive of a late alteration process. Even the more pristine glasses (inclusion glasses of group A) have also been affected by the metasomatic exchange reactions as is indicated by the fact that their $\mathrm{Fe} / \mathrm{Mg}$ ratio is in equilibrium with that of their hosts (Fig. 15) and that their Fe/Mn ratio is chondritic.

The most primitive glasses have an $\mathrm{Al}_{2} \mathrm{O}_{3}$ content comparable to that of glass inclusions in olivines of carbonaceous chondrites (Varela et al., 2002a), and its variation also seems to be of secondary origin, as is shown by the anticorrelation of $\mathrm{Al}_{2} \mathrm{O}_{3}$ and $\mathrm{FeO}$ in inclusion glasses and glass pockets (Fig. 7). The exchange of a framework builder cation such as $\mathrm{Al}^{3+}$ with a network modifier such as $\mathrm{Fe}^{2+}$ in the structure of these glasses does not seem to be possible because of the strong bonds within the framework. However, apparently only part of the $\mathrm{Al}^{3+}$ present took part in building the mainly $\mathrm{Si}-\mathrm{O}$ framework of the glass; the rest, which occupied octahedral sites, was replaceable and was indeed in part replaced by $\mathrm{Fe}^{2+}$.

Glass inclusions also register the continuous addition of the secondarily introduced elements $\mathrm{Fe}$ and $\mathrm{Mn}$ until reaching the chondritic values that characterizes all other glasses (Fig. 12).Volatile elements (e.g., C, N) were retained only by those glasses that were shielded by olivines. The increasingly oxidizing conditions that affected this rock could also have helped to transform the original refractory carrier phases of carbon and nitrogen (carbides, nitrides) into volatile species $\left(\mathrm{CO}, \mathrm{N}_{2}\right)$, similar to what has been proposed for glass inclusions in olivines of carbonaceous chondrites. Because glasses filling open spaces lack protection, they apparently lost $\mathrm{CO}, \mathrm{SO}_{3}$, and $\mathrm{N}_{2}$ by degassing. This process is recorded by abundant foamy glass.

In the course of the vapor-liquid-solid condensation process, large quantities of liquids could have formed that coagulated and gave rise to the most common types of glasses. Evidence that the melt did not move over some distance but rather stayed concentrated in some places indicates that quenching must have been very fast. Because these glasses occupy open spaces, it is likely that they could have behaved as open systems and, thus, recorded the final conditions prevailing during D'Orbigny formation. These glasses seem to have been able to maintain their communication with the vapor phase and thus were constantly buffered by it. The flat, unfractionated REE pattern at $\sim 10-20$ $\times$ CI abundances could indicate that trace elements were diffusionally buffered by the vapor that was oversaturated in all refractory elements. This situation appears to have been different only in a few cases, when glasses shielded by their hosts lost their possibility of being buffered (indicated, for example, by the slight REE fractionation of some glass pockets and glass inclusions).

All these pieces of evidence suggest that D'Orbigny glasses had an origin similar to those of glass inclusions in olivine of carbonaceous chondrites, i.e., condensation from a vapor with relative abundances of condensable elements similar to those in the solar nebula.

\section{CONCLUSIONS}

The new angrite D'Orbigny is exceptionally rich in glass. Glasses fill open spaces like hollow shells and druses and form glass pockets and glass inclusions in olivines. Their petrographic occurrence clearly indicates that the most common glasses have been incorporated after the formation of the empty spaces in the rock. However, the lack of interconnected glass veins crosscutting the rock strongly supports the view that glasses were not introduced from outside the rock. Chemical data as well as petrographic observations exclude formation of D'Orbigny glasses by shock or a partial melting process. Because these glasses share many of their features with those of glass inclusions in olivines of carbonaceous chondrites, we propose that the mechanism by which glasses in D'Orbigny were formed is similar to that invoked for inclusion glasses in olivines of carbonaceous chondrites. That is, they have formed by a vapor-liquid-solid olivine growth. Similar to those in glass inclusions in olivines of carbonaceous chondrites, trace element abundances in D'Orbigny glasses appear to be the result of a precipitation process governed by volatility. The relative abundances of all refractory lithophile elements in the glass are chondritic, which suggests that the source for the glass had chondritic refractory elemental relative abundances. The abundances of major refractory elements are $10 \times \mathrm{CI}$ and those of $\mathrm{FeO}$ and $\mathrm{MnO}$ are similar to those in CI chondrites.

In addition to the well-known Ca-Na (Kurat and Kracher, 1980) and Mg-Fe (Kurat, 1988; Dohmen et al., 1998) metasomatic exchange reactions observed in chondrites, here we have identified a novel mechanism for alteration of glass and rock compositions. Our data show that the final composition of glass in D'Orbigny and in angrites is probably the result of an exchange of $\mathrm{Al}$ and $\mathrm{Sc}$ for $\mathrm{Fe}$ and other moderately volatile elements. This process could be the cause of the fractionated $\mathrm{Ca} / \mathrm{Al}$ ratio and $\mathrm{Sc}$ depletion in angrites, eucrites, and their glasses.

However, the main difference between D'Orbigny glasses and glass inclusions in olivines of carbonaceous chondrites is that the chemical compositions of the D'Orbigny glasses reflect 
their behavior as both, closed system (glasses shielded by their host crystals) and open system. Glasses of the former type (glass inclusions and glass pockets) show a wider compositional variation than those of the latter, whose composition mainly reflects crystal fractionation and the metasomatic exchange reactions with an external source. Because glass inclusions in olivine were shielded by their hosts, they were able to keep a more pristine composition than all other glasses. The most common glasses in D'Orbigny (representing open systems) also document the metasomatic exchange reactions and were able to record the highly oxidizing conditions that appear to have affected the D'Orbigny bulk rock. Because the Fe/Mn ratio of the glass (and rock) is chondritic, the metasomatic event that added $\mathrm{Fe}$ and $\mathrm{Mn}$ to the rock must have been fed by a chondritic source.

All these features point towards a primitive origin of D'Orbigny glasses. A condensation origin from a reservoir with chondritic relative abundances of refractory and moderately volatile elements seems to be likely.

Acknowledgments-The authors want to thank the owner of D'Orbigny for generously providing samples. We thank Mike Tubrett and Gabor Dobosi, Memorial University, St. John's, for help with the LA-ICP-MS analyses and Misha Nazarov for help with the crystallization calculations. The thorough reviews of Katharina Lodders, S. Mostefaoui, and an anonymous reviewer and the constructive comments of the associate editor C. Koeberl considerably improved the manuscript. Financial support was received from FWF (P-13975-GEO) and the Friederike und Oskar Ermann - Fonds, Austria, CEA, France, NASA grant NAG 5-9801, and CONICET, Fundación Antorchas (P-14022/91) and SECYT (P 07- 08176), Argentina.

\section{Associate editor: C. Koeberl}

\section{REFERENCES}

Anders E. and Grevesse M. (1989) Abundances of the elements: Meteoritic and solar. Geochim. Cosmochim. Acta 53, 197-214.

Ariskin A. A., Petaev M., Borisov A., and Barmina G. S. (1997) METEOMOD: A numerical model for the calculation of meltingcrystallization relationships in meteoritic igneous systems. Meteorit. Planet. Sci. 32, 123-133.

Dohmen R., Chakraborty S., Rammensee W., and Palme H. (1998) Solid-solid reactions mediated by a gas phase: An experimental study of reaction progress and the role of surfaces in the system olivine + Fe-metal. Am. Mineralogist 83, 970-984.

Givargizov E. I. (1987) Highly Anisotropic Crystals. D. Reidel, Dordrecht, $394 \mathrm{pp}$.

Goodrich C. A. (1988) Petrology of the unique achondrite LEW 86010. Lunar Planet. Sci. XIX. Lunar Planet. Inst., Houston. 399-400 (abstr.).

Green T. H. (1994) Experimental studies of trace-element partitioning applicable to igneous petrogenesis-Sedona 16 years later. Chem. Geol. 117, 1-36.

Hashimoto A. (1992) The effect of $\mathrm{H}_{2} \mathrm{O}$ gas on volatiles of planetforming major elements: I. Experimental determination of thermodynamic properties of Ca-, Al-, and Si-hydroxide gas molecules and its application to the solar nebula. Geochim. Cosmochim. Acta 51, 1685-1704.

Jagoutz E., Jotter R., Varela M. E., Zartman R., Kurat G., and Lugmair G. W. (2002) Pb-U-Th isotopic evolution of the D'Orbigny angrite. Lunar Planet. Sci. XXXII. Lunar Planet. Inst., Houston. \#1043 (abstr.).

Jones J. H., Treiman A. H., Janssens M.-J., Wolf R., and Ebihara M. (1988) Core formation on the eucrites parents body, the moon and the AdoR parent body. Meteoritics 23, 276-277.

Jotter R., Jagoutz E., Varela M. E., Zartman R., and Kurat G. (2002) Pb isotopes in glass and carbonates of the D'Orbigny angrite. Meteorit. Planet. Sci. 37, A73 (abstr.).
Jurewicz A. J. G., Mittlefehldt D. W., and Jones J. H. (1993) Experimental partial melting of the Allende (CV) and Murchison (CM) chondrites and the origin of asteroidal basalts. Geochim. Cosmochim. Acta 57, 2123-2139.

Kennedy A. K., Lofgren G. E., and Wasserburg G. J. (1993) An experimental study of trace element partitioning between olivine, orthopyroxene and melt in chondrules: Equilibrium values and kinetics effects. Earth Planet. Sci. Lett. 115, 177-195.

Kurat G. (1988) Primitive meteorites: An attempt towards unification. Phil. Trans. R. Soc. Lond. A325, 459-482.

Kurat G. and Kracher A. (1980) Basalts in the Lancé carbonaceous chondrite. Z. Naturforsch. 35a, 180-190.

Kurat G., Varela M. E., Hoppe P., and Clocchiatti R. (1997) Glass inclusions in Renazzo olivine: Condensates from the solar nebula? Meteorit. Planet. Sci. 32, A76 (abstr.).

Kurat G., Brandstätter F., Clayton R., Nazarov M. A., Palme H., Schultz L., Varela M. E., Wäsch E., Weber L., and Weckwerth G. (2001a) D'Orbigny: A new and unusual angrite. Lunar Planet. Sci. XXXII. Lunar Planet. Inst., Houston. \#1753 (abstr.).

Kurat G., Varela M. E., Brandstätter F., Wäsch E., and Nazarov M. A. (2001b) D'Orbigny: A new window into angrite genesis. Lunar Planet. Sci. XXXII. Lunar Planet. Inst., Houston. 1737 (abstr.).

Kurat G., Ntaflos T., Brandstätter F., Varela M. E., Sylvester P. J., and Nazarov M. A. (2001c) Trace element contents of major phases of the D'Orbigny angrite. Meteorit. Planet. Sci. 36, A108 (abstr.).

Kurat G., Varela M. E., Brandstätter F., Weckwerth G., Clayton R., Weber H. W., Schultz L., Wäsch E., and Nazarov M. A. (2003) D'Orbigny: A non-igneous angritic achondrite? Geochim. Cosmochim. Acta (in press).

Longhi J. (1999) Phase equilibrium constraints on angrite petrogenesis. Geochim. Cosmochim. Acta 63, 573-585.

Lugmair G. W. and Galer S. J. C. (1992) Age and isotopic relationships among the angrites Lewis Cliff 86010 and Angra dos Reis. Geochim. Cosmochim. Acta 56, 1673-1694.

McKay G. and Weill D. F (1977) KREEP petrogenesis revisited. Proc. Eighth Lunar Sci. Conf. 8th, Houston, TX, March 14-18, vol 2, Pergamon Press, New York.

McKay G., Lindstrom D., Le L., and Yang S. R. (1988) Experimental studies on synthetic LEW86010 analogs: Petrogenesis of a unique achondrite. Lunar Planet. Sci. XIX. Lunar Planet. Inst., Houston. 760-761 (abstr.)

McKay G., Crozaz G., Wagstaff J., Yang S.-R., and Lundberg L. (1990) A petrographic, electron microprobe and ion probe study of mini-angrite Lewis Cliff887051. Lunar Planet. Sci. XIX. Lunar Planet. Inst., Houston. 771-772 (abstr.).

McKay G., Le L., Wagstaff J., and Crozaz G. (1994) Experimental partitioning of rare earth elements and strontium: Constraints on petrogenesis and redox conditions during crystallization of Antarctic angrite Lewis Cliff 86010. Geochim. Cosmochim. Acta 58, 2911-2919.

Mikouchi T., Miyamoto M., and McKay G. (1996) Mineralogy study of angrite Asuka-881371: Its possible relation to angrite LEW 87051. Proc. NIPR Symp. Antarct. Meteorites 9, 174-188.

Mikouchi T, McKay G (2001). Mineralogical investigation of D'Orbigny: A new angrite showing close affinities to Asuka 881371, Sahara 99555 and Lewis Cliff 87051. Lunar Planet. Sci. XXXII. Lunar Planet. Inst., Houston. \#1876 (abstr.).

Mittlefehldt D. W. and Lindstrom M. M. (1990) Geochemistry and genesis of angrites. Geochim. Cosmochim. Acta 54, 3209-3218.

Mittlefehldt D. W., McCoy T. J., Goodrich C. A., and Kracher A. (1998) Non-chondritic meteorites from asteroidal bodies. In Planetary Materials (ed. J. J. Papike), Rev. Mineral., vol. 36, Mineral. Soc. America, 4, 1-195.

Mittlefehldt D. W., Killgore M., and Lee M. T. (2001). Petrology and geochemistry of the new angrite D'Orbigny. Lunar Planet. Sci. XXXII. Lunar Planet. Inst., Houston. \#2057 (abstr.).

Mittlefehldt D. W., Killgore M., and Lee M. T. (2002) Petrology and geochemistry of D'Orbigny, geochemistry of Sahara 99555, and the origins of angrites. Meteorit. Planet. Sci. 37, 345-369.

Pearce N. J. G., Perkins W. T., Westgate J. A., Gorton M. P., Jackson S. E., Neal C. R., and Chenery S. P. (1997) A compilation of new and published major and trace element data for NIST SRM 610 and NIST SRM 612 glass reference materials. Geostandards Newsletter 21, 115-144. 
Prinz M., Keil K., Hlava P. F., Berkley J. L., Gomes C. B., and Curvello W. S. (1977) Studies of Brazilian meteorites III. Origin and history of the Angra dos Reis achondrite. Earth Planet. Sci. Lett. 35, 317-330.

Prinz M., Weisberg M. K., and Nehru C. E. (1988) LEW 86010, a second angrite: Relationship to CAI's and opaque matrix. Lunar Planet. Sci. XIX. Lunar Planet. Inst., Houston. 949-950 (abstr.).

Prinz M., Weisberg M. K., and Nehru C. E. (1990) LEW 87051, a new angrite: Origin in a Ca-Al-enriched planetesimal? Lunar Planet. Sci. XXI. Lunar Planet. Inst., Houston. 979-980 (abstr.).

Prinz M. and Weisberg M. K. (1995) Asuka 881371 and the angrites: Origin in a heterogeneous, CAI-enriched, differentiated, volatiledepleted body. Antarct. Meteorites 20, 207-210 (abstr.).

Roeder P. L. and Emslie R. V. (1970) Olivine-liquid equilibrium. Contrib. Mineral. Petrol. 29, 275-289.

Treiman A. H. (1989) An alternate hypothesis for the origin of Angra dos Reis: Porphyry, not cumulate. Proc. Lunar Planet. Sci. Conf. 19, 443-450.

Varela M. E., Métrich N., Bonnin-Mosbah M., and Kurat G. (2000) Carbon in glass inclusions of Allende, Vigarano, Bali and Kaba (CV3) olivines. Geochim. Cosmochim. Acta 64, 3923-3930.

Varela M. E., Kurat G., Brandstätter F., Bonnin-Mosbah M., and Métrich N. (2001a). Glasses in the D’Orbigny angrite. Lunar Planet. Sci. XXXII. Lunar Planet. Inst., Houston. \#1803 (abstr.).

Varela M. E., Kurat G., Ntaflos T., Brandstätter F., and Sylvester P. J. (2001b) Trace elements in glass of the D'Orbigny angrite. Meteorit. Planet. Sci. 36, A211 (abstr.).
Varela M. E., Kurat G., Hoppe P., and Brandstätter F. (2002a) Chemistry of glass inclusions in CR (Renazzo type) carbonaceous chondrites. Geochim. Cosmochim. Acta 66, 1663-1679.

Varela M. E., Kurat G., Hoppe P., and Weisberg M. (2002b). Chemistry of glass inclusions in olivine of a dark inclusion and the host Allende CV3 chondrite. Lunar Planet. Sci. XXXIII. Lunar Planet. Inst., Houston. \#1190 (abstr.).

Varela M. E., Bonnin-Mosbah M., Kurat G., and Gallien J. P. (2003) Nitrogen micro-analysis of glass inclusions in chondritic olivines by nuclear reaction. Geochim. Cosmochim. Acta 67, 1247-1257.

Warren P. H. and Davis A. M. (1995) Consortium investigation of the Asuka-881371 angrite: Petrographic, electron microprobe and ion probe observations. Antarct. Meteorites 20, 257-260 (abstr.).

Wasserburg G. J., Tera F., Papanastassiou D. A., and Huneke J. C. (1977) Isotopic and chemical investigation of Angra dos Reis. Earth Planet. Sci. Lett. 35, 294-316.

Yanai K. (1994) Angrite Asuka-881371: Preliminary examination of a unique meteorite in the Japanese collection of Antarctic meteorites. Proc. NIPR Symp. Antarct. Meteorites 7, 30-41.

Yanai K. (2000) Achondritic crystalline meteorite specimen Ya 1154: A unique dendritic texture with angrite composition. Meteorit. Planet. Sci. 35, A174 (abstr.).

Zinner E. and Crozaz G. (1986) A method for the quantitative measurement of rare earth elements in the ion probe. Int. J. Mass Spectrom. Ion Processes 69, 17-38. 